\title{
Carbon catalysts for electrochemical hydrogen peroxide production in acidic media
}

oli, Viktor; Yang, Sungeun; Révay, Zsolt; Stephens, Ifan E.L.; Chorkendorff, Ib

\section{Published in:}

Electrochimica Acta

Link to article, DOI:

10.1016/j.electacta.2018.03.170

Publication date:

2018

Document Version

Peer reviewed version

Link back to DTU Orbit

Citation (APA):

oli, V., Yang, S., Révay, Z., Stephens, I. E. L., \& Chorkendorff, I. (2018). Carbon catalysts for electrochemical hydrogen peroxide production in acidic media. Electrochimica Acta, 272, 192-202.

https://doi.org/10.1016/j.electacta.2018.03.170

\section{General rights}

Copyright and moral rights for the publications made accessible in the public portal are retained by the authors and/or other copyright owners and it is a condition of accessing publications that users recognise and abide by the legal requirements associated with these rights.

- Users may download and print one copy of any publication from the public portal for the purpose of private study or research.

- You may not further distribute the material or use it for any profit-making activity or commercial gain

- You may freely distribute the URL identifying the publication in the public portal 


\section{Accepted Manuscript}

Carbon catalysts for electrochemical hydrogen peroxide production in acidic media

Viktor Čolić, Sungeun Yang, Zsolt Révay, Ifan E.L. Stephens, Ib Chorkendorff

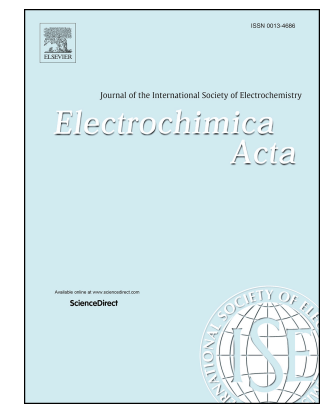

PII: S0013-4686(18)30687-X

DOI: $\quad$ 10.1016/j.electacta.2018.03.170

Reference: $\quad$ EA 31536

To appear in: Electrochimica Acta

Received Date: 23 October 2017

Revised Date: 22 March 2018

Accepted Date: 27 March 2018

Please cite this article as: V. Čolić, S. Yang, Z. Révay, I.E.L. Stephens, I. Chorkendorff, Carbon catalysts for electrochemical hydrogen peroxide production in acidic media, Electrochimica Acta (2018), doi: 10.1016/j.electacta.2018.03.170.

This is a PDF file of an unedited manuscript that has been accepted for publication. As a service to our customers we are providing this early version of the manuscript. The manuscript will undergo copyediting, typesetting, and review of the resulting proof before it is published in its final form. Please note that during the production process errors may be discovered which could affect the content, and all legal disclaimers that apply to the journal pertain. 


\title{
Carbon Catalysts for Electrochemical Hydrogen Peroxide Production in
}

\section{Acidic Media}

\author{
Viktor Čolića ${ }^{\mathrm{a}}$, Sungeun Yang ${ }^{\mathrm{a}}$, Zsolt Révay ${ }^{\mathrm{b}}$, Ifan E.L. Stephens ${ }^{\mathrm{a}, \mathrm{c}}$, Ib Chorkendorff, ${ }^{\mathrm{a},{ }^{*}}$ \\ ${ }^{\mathrm{a}}$ Section for Surface Physics and Catalysis, Department of Physics, Building 312, Technical \\ University of Denmark (DTU), DK-2800, Kgs. Lyngby, Denmark \\ ${ }^{\mathrm{b}}$ Heinz Maier-Leibnitz Zentrum (MLZ), Technische Universität München, Lichtenbergstrasse 1, \\ 85787 Garching, Germany \\ ${ }^{\mathrm{c}}$ Department of Materials, Imperial College London, Royal School of Mines, Exhibition Road \\ SW7 2AZ, London, United Kingdom \\ *Corresponding author: ibchork@fysik.dtu.dk
}

\begin{abstract}
Hydrogen peroxide is a commodity chemical, as it is an environmentally friendly oxidant. The electrochemical production of $\mathrm{H}_{2} \mathrm{O}_{2}$ from oxygen and water by the reduction of oxygen is of great interest, as it would allow the decentralised, on-site, production of pure $\mathrm{H}_{2} \mathrm{O}_{2}$. The ability to run the reaction in an acidic electrolyte with high performance is particularly important, as it would allow the use of polymer solid electrolytes and the production of $\mathrm{pH}$-neutral hydrogen peroxide. Carbon catalysts, which are cheap, abundant, durable and can be highly selective show promise as potential catalysts for such systems. In this work, we examine the electrocatalytic performance and properties of seven commercially available carbon materials
\end{abstract}


for $\mathrm{H}_{2} \mathrm{O}_{2}$ production by oxygen electroreduction. We show that the faradaic efficiencies for the reaction lie in a wide range of 18-82\% for different carbon catalysts. In order to determine the cause of these differences, we employ prompt gamma ray / neutron activation analysis and XPS measurements to assess the contribution of heteroatoms and defects, as well as low temperature $\mathrm{N}_{2}$-adsorption and transmission electron microscopy to elucidate the particle size, shape, BET surface area and porosity. We find that the surface oxygen groups, nitrogen and sulphur content display effects that are not straightforward, because their chemical state is likely significant. The metal content (when present in the order of magnitude of $\sim 10$ ppm) is not a straightforward indicator of the electrocatalytic performance for this reaction. XPS and BET data indicate that carbons displaying high selectivities for the 2-electron process contain more aliphatic-like, "defect" structures on the surface.

\section{Introduction}

Hydrogen peroxide is an environmentally friendly oxidant, considered crucial for future "green chemistry". It is widely used in bleaching, chemical synthesis and water disinfection, with an annual production of about $5,000,000 \mathrm{t}[1] . \mathrm{H}_{2} \mathrm{O}_{2}$ is currently produced in the so-called "anthraquinone" or "Riedel-Pfleiderer" process, developed between 1935 and 1945[2], which is a complex procedure involving consecutive batch hydrogenation/oxygenation steps of anthraquinones. The process requires large-scale facilities, it is highly energy consuming and generates considerable amounts of waste. Since the implementation of the anthraquinone process necessitates centralised production, $\mathrm{H}_{2} \mathrm{O}_{2}$ is generally produced in a concentrated form in order to reduce transport costs, however, for many applications only dilute solutions are needed 
(usually 2-5 \%)[3]. A more decentralized on-site production of $\mathrm{H}_{2} \mathrm{O}_{2}$ would be more attractive[4,5], as it would negate the need for the transport of concentrated $\mathrm{H}_{2} \mathrm{O}_{2}$.

The oxygen reduction reaction (ORR) is one of the most studied reactions in contemporary electrocatalysis, mainly due to its significance in energy conversion systems. It can, in principle, proceed through two competing pathways: the four-electron, which results in the formation of water; and the two-electron one, where hydrogen peroxide is the final product. The former is desired in fuel cells and batteries since it enables higher energy efficiency[6]. However, the twoelectron pathway, which could potentially enable the electrochemical production of $\mathrm{H}_{2} \mathrm{O}_{2}$, has drawn increasing attention[7-11]. The electrochemical production of $\mathrm{H}_{2} \mathrm{O}_{2}$ would ideally allow on-site production requiring only air (oxygen), water, and electricity, which could be supplied from renewable sources. The construction of such devices could potentially allow the provision of clean drinking water in remote regions and developing countries[12]. The advancement of electrochemical $\mathrm{H}_{2} \mathrm{O}_{2}$ production is primarily limited by the development of catalysts with a high faradaic efficiency for the electroreduction of oxygen to $\mathrm{H}_{2} \mathrm{O}_{2}$, which is competing with the fourelectron process.

The oxygen reduction to hydrogen peroxide on carbon materials has been shown to be highly selective in alkaline media[13-16], even simple glassy carbon is a relatively good catalyst for the 2-electron process under these conditions (see. e.g. [17]). However, alkaline solutions of $\mathrm{H}_{2} \mathrm{O}_{2}$ are unstable and their applicability is limited. Therefore, the production of pure, pH-neutral, $\mathrm{H}_{2} \mathrm{O}_{2}$ solutions would be preferable[18]. The use of solid electrolytes allows easy separation of the electrolyte from the product; however, this necessitates acidic reaction conditions[19,20], particularly considering the instability of $\mathrm{OH}^{-}$-conducting electrodes in the presence of $\mathrm{H}_{2} \mathrm{O}_{2}$ [21]. We previously reported a class of catalysts based on $\mathrm{Pt}$ and $\mathrm{Pd}$ alloyed with $\mathrm{Hg}$, which are 
highly active and selective for $\mathrm{H}_{2} \mathrm{O}_{2}$ generation in acidic media [22,23]. However, the use of mercury limits the potential application of these materials due to its toxicity. The implementation of other promising catalysts such as Au-Pd[24] could also be limited by the high price of the precious metals and problems regarding upscaling. Single atom catalysts can show considerable selectivities, however, their stability limits their application [25]. Conversely, carbon-based materials, which are stable, inexpensive and environment-friendly, are a promising alternative. Therefore, the performance of various carbon-based catalysts for the ORR to $\mathrm{H}_{2} \mathrm{O}_{2}$ has been investigated lately[19,26-28]. For a catalyst to be applicable in real-world devices, it should generally possess a high faradaic efficiency (FE) and desirably a high partial current density for $\mathrm{H}_{2} \mathrm{O}_{2}$ production, as well as a low tendency to decompose it.

Among the important factors that influence the selectivity of carbon-based catalysts are the transition metal content[29] and the presence of surface functionalities (primarily $\mathrm{N}-[30,31]$, $\mathrm{B}$ [32], $\mathrm{P}[33]$ and S-containing [34,35] surface groups). Surface "defects" [36], particularly the edges[37,38] been reported to play a significant role. Metal impurities can influence the ORR even when present at very low concentrations, causing controversy on the nature of certain carbon-based catalysts[29]. Numerous reports show that the presence of transition metals, such as $\mathrm{Fe}[39,40]$ and $\mathrm{Co}[9,41]$ plays a strong role. Even concentrations in the range of hundreds or even tens of ppm can influence their electrocatalytic properties[42,43]. The presence of transition metals could potentially influence the selectivity and activity of carbon materials in several ways: by being incorporated into specific active sites[44], catalysing the creation of new active sites[45], and catalysing $\mathrm{H}_{2} \mathrm{O}_{2}$ decomposition to $\mathrm{H}_{2} \mathrm{O}$ and $\mathrm{O}_{2}$ [46]. 
The presence of non-metallic heteroatoms, such as $\mathrm{O}, \mathrm{B}, \mathrm{N}$ and $\mathrm{S}$, shifts the selectivity of carbon catalysts towards water generation by the 4-electron process (see, e.g., ref $[47,48]$ ). Their impact is explained by the idea that the foreign atoms change the electronic structure of carbon atoms in the vicinity. Zhang and Dai explain their influence in the terms of the redistribution of charge, which changes the $\mathrm{O}_{2}$ chemisorption properties effectively influencing the $\mathrm{O}-\mathrm{O}$ bonding[49]. The changes in the strength of the O-O bond can then be reflected in differences in the selectivity for the ORR. Numerous reports show that oxygenated surface groups influence many properties of carbon materials, such as the redox capacity[50], conductivity[51], adsorption [52,53] their properties as catalyst supports[54], electrochemical activity[13,55-57] and photocatalytic activity[58].

Behm and coworkers showed that the selectivity of the ORR is linked with catalyst loading and mass transport effects[59,60]. The selectivity is highly influenced by the rate of $\mathrm{H}_{2} \mathrm{O}_{2}$ readsorption and further reduction to $\mathrm{H}_{2} \mathrm{O}$. Thus, decreased catalyst loading and increased electrolyte flow rate favour $\mathrm{H}_{2} \mathrm{O}_{2}$ generation. The thicker catalyst layer could potentially be detrimental for the faradaic efficiency, as $\mathrm{H}_{2} \mathrm{O}_{2}$ diffusion away from the surface would be inhibited and it would be more likely to undergo further reduction to $\mathrm{H}_{2} \mathrm{O}$.

In order to assess the faradaic efficiencies (FEs) of different carbon materials for the 2electron oxygen reduction, the electrocatalytic performance of seven commercially available high surface area carbon materials was tested in acidic electrolyte, $0.1 \mathrm{M} \mathrm{HClO}_{4}$, in a threeelectrode setup with a stationary working electrode. We chose this setup in order to test the catalyst under conditions similar to those used in MEAs, at the same time keeping the system simple enough to be able to control the potential of the working electrode well and allow a facile assessment of the properties of the catalyst. Furthermore, we apply prompt gamma-ray activation 
/ neutron activation analysis (PGAA/NAA), X-ray photoelectron spectroscopy (XPS), $\mathrm{N}_{2}$ adsorption for BET surface area and porosity determination, and transmission electron microscopy (TEM) to characterize these carbon materials and correlate their properties with their electrocatalytic performance.

\section{Experimental}

The following carbon samples were examined in this work: BP2000, PBX51, LITX 200, Vulcan XC72R (Cabot, USA), ENSACO 350G, C-Nergy Super C-65 (Imerys, Switzerland), and YP-80F (Kuraray, Japan). The carbons were sprayed using an H\&S Ultra Airbrush pistol 125503 (Harder\&Steenbeck, Germany) spraying gun onto an H15 (Freudenberg, Germany) gas diffusion layer (GDL) on an area of approximately $14 \times 14 \mathrm{~mm}\left(c a 2 \mathrm{~cm}^{2}\right)$. The ink was prepared by making a suspension of $40 \mathrm{mg}$ of carbon material in a liquid mixture prepared from ethanol, ultrapure water and $5 \%$ perfluarinated Nafion ${ }^{\circledR}$ solution in aliphatic alcohols (Sigma Aldrich, Germany). Contact with metals was genetrally avoided during electrode preparation. The suspension was sonicated for 20 minutes using a UP50H ultrasonic processor (Hielscher, Germany), until a liquid with no visible agglomerates and homogeneous appearance was obtained. The amount of deposited carbon (and Nafion ${ }^{\circledR}$ ) was determined by measuring the weight of GDL before and after the spraying, taking into account the composition of the ink.

The electrochemical selectivity was measured in a typical three-electrode setup (see SI1), consisting of a GDL sprayed with the investigated carbon material with an area of $c a 2 \mathrm{~cm}^{2}$ acting as a working electrode, a graphite rod counter electrode (Graphite rod Grade 1; Ted Pella, Inc., USA), and a mercury-mercurous sulphate reference electrode (SI Analytics, Germany). GDL without sprayed carbon can reduce $\mathrm{O}_{2}$ as well, but its contribution to the overall activity 
and selectivity is negligible due to its low activity. The volume of the working electrolyte was 15 mL. All potentials in this work are referred to the reversible hydrogen electrode (RHE) scale. Electrochemical measurements were carried out using a Bio-Logic VMP2 (Bio-Logic, France) potentiostat. The electrolyte was $\mathrm{O}_{2}$-saturated (5.0 AGA Gas AB, Sweden) $0.1 \mathrm{M} \mathrm{HClO}_{4}$ prepared from $70 \% \mathrm{HClO}_{4}$ (Merck Suprapur ${ }^{\circledR}$, Germany) by dilution with ultrapure water from a Millipore Synergy ${ }^{\circledR} \mathrm{uV}$ water purification system. The $\mathrm{H}_{2} \mathrm{O}_{2}$ concentration in the solution after electrochemical measurements was determined by the titration of a $5 \mathrm{~mL}$ sample of the electrolyte from the working electrolyte compartment with $0.02 \mathrm{M} \mathrm{KMnO}_{4}$ (Titripur®, Sigma Aldrich, Germany) solution with concurrent stirring using a magnetic stirrer, by adding $10 \mu \mathrm{L}$ aliquots until coloration was observed. The faradaic efficiencies were calculated taking into account the amount of detected $\mathrm{H}_{2} \mathrm{O}_{2}$ and the overall amount of charge passed through the system at $-0.2 \mathrm{~V} v s$. RHE, which was $c a 10 \mathrm{C}$ in all measurements.

The BET surface areas of the carbon materials were determined by $\mathrm{N}_{2}$ adsorption at $77 \mathrm{~K}$ using a Micromeritics ASAP 2020 Surface Area and Porosity Analyzer instrument. MicroActive for ASAP 2020 Version 6.0 software was used for the processing of the obtained data. Before the measurement, the sample was outgassed for $4 \mathrm{~h}$ at $200^{\circ} \mathrm{C}$ at $13 \mu \mathrm{bar}$. The specific surface area was determined by a multipoint Brunauer-Emmett-Teller (BET) analysis. The porosity was determined by the t-plot method.

TEM samples were prepared by suspending the carbon material in ethanol and applying it to a lacy carbon film 300 mesh $\mathrm{Cu}$ (50) TEM grid (Agar Scientific, UK). The micrograph with Nafion was prepared by depositing the ink with the same contents as used for spraying to an identical lacy carbon-Cu mesh. Bright-field TEM images were taken with a Tecnai T20 G2 S- 
TEM (FEI, USA). The thermionic electron gun with a $\mathrm{LaB}_{6}$ filament operated at $200 \mathrm{keV}$ high tension. The magnifications were between 29000 and 195000 times. Typical exposure times were $0.5-5$ s. Images were processed using the DigitalMicrograph 1.85 and ImageJ $1.51 \mathrm{j} 8$ software.

PGAA/NAA was conducted at the FRM II neutron source of the Technical University of Munich with a cold neutron spectrum from NL4b (last section of $5.8 \mathrm{~m}$ elliptical focusing) with an average energy of $1.83 \mathrm{meV}(6.7 \AA)$. Beam size: $11 \times 16 \mathrm{~mm}^{2}$. Neutron flux max.: $510^{10} \mathrm{n}$ $\mathrm{cm}^{-2} \mathrm{~s}^{-1}$ thermal $\mathrm{n}$. eq. The typical irradiation times were about 10 hours. A Compton-suppressed spectrometer was used (60 \% HPGe detector surrounded by a BGO scintillator and connected in anticoincidence mode). The signal was processed using a DSpec-50 digital spectrometer manufactured by Ortec. A low-background counting chamber was used for the acquisition of decay gamma spectra after activating the samples in the beam. A $30 \%$ HPGe detector is used with a DSpec-50 unit also equipped with a Compton suppressor (using NaI scintillator). The sample masses were $c a 0.2-0.5 \mathrm{~g}$. Four decay spectra were acquired after the irradiation: typically for $30 \mathrm{~min}$, then for $1-2 \mathrm{~h}$, and then for $10-20 \mathrm{~h}$, and another long measurement after 4-5 days. Determination of the elemental composition of samples using the Excel macro and Excel sheet package ProSpeRo[61]. The instrument is described in detail in ref [62]. The $\mathrm{H}$ content was determined using PGAA, while the metal impurities were analysed using NAA, i.e., from the decay gamma spectra of the irradiated samples.

A Theta Probe (Thermo Scientific, USA) instrument with a monochromatized Al K $\alpha$ (1486.6 eV) source was used for the recording of XPS spectra, which were obtained with a pass energy of $100 \mathrm{eV}$. The spectra were recorded with a step/resolution of $0.1 \mathrm{eV}$ and dwell time of $50 \mathrm{~ms}$. 
The beam size was $50 \mu \mathrm{m}$ for all measurements. The atomic concentrations of $\mathrm{C}$ and $\mathrm{O}$ were quantified by integration of the $\mathrm{C} 1 \mathrm{~s}$ and $\mathrm{O} 1 \mathrm{~s}$ peaks, respectively, using a Shirley-type background. The spectra were processed in the Avantage v5.982 software. The samples for XPS analysis were prepared by the deposition of the carbon powders on Si chips by drop-casting from an ethanol suspension. In order to make sure that the recorded spectra are indeed of the examined carbon materials, the absence of the Si-peaks ( $\mathrm{Si} 2 \mathrm{~s}$ and 2p3/2 observed at $156.2 \mathrm{eV}$ and 105.2 eV BE) was considered indicative that the carbon black material was being probed (see SI2).

Cyclic voltammetry (CV) and electrochemical impedance spectroscopy (EIS) were conducted in an RRDE configuration at 1600 r.p.m. CV was conducted in a potential range 0$1.62 \mathrm{~V} v s$. RHE at 10, 25, 50, 75 and $100 \mathrm{mV} / \mathrm{s}$. EIS was conducted in the potential range from OCV to $-0.2 \mathrm{~V}$ vs RHE with 20 potential steps. with a $25 \mathrm{mV}$ sinusoidal amplitude in a frequency range of $200 \mathrm{KHz}-1 \mathrm{~Hz}$ with 6 points per decade with logarithmic spacing. The fitting of the impedance spectra was done according to the procedure described in ref [63].

The carbons were subjected to the following treatments: (1.) Liquid phase oxidation: $0.1 \mathrm{~g}$ of carbon in $1 \% \mathrm{H}_{2} \mathrm{O}_{2}$ for $6 \mathrm{~h}$, followed by filtration and thorough rinsing. (2.) Gas phase oxidation: heating up $0.1 \mathrm{~g}$ of the carbon powder in air in an ATS 3210-1.62-12-15 Tube Furnace (Applied Test Systems, USA) with a $10^{\circ} \mathrm{C} / \mathrm{min}$ ramp to a set temperature (3.) Thermal treatment: Heating up in tube furnace with a $10^{\circ} \mathrm{C} / \mathrm{min}$ ramp to the desired temperature 900 , $1000^{\circ} \mathrm{C}$ and held at that temperature for $2 \mathrm{~h}$ in an $\mathrm{Ar}$ (5.0 AGA Gas AB, Sweden) atmosphere, and then left to cool in an Ar-stream. (4.) Gas phase reduction: Heating up in a tube furnace with a $10^{\circ} \mathrm{C} / \mathrm{min}$ ramp to $500^{\circ} \mathrm{C}$ and held at that temperature for $2 \mathrm{~h}$ in an $\mathrm{H}_{2}$ (5.0 AGA Gas $\mathrm{AB}$, Sweden) atmosphere, and then left to cool in a stream of the same gas. 


\section{Results}

In order to elucidate the physical properties of the carbon materials TEM measurements were performed to visualize the carbon particles and low temperature $\mathrm{N}_{2}$-adsorption in order to assess the surface area and porosity. Examples of TEM micrographs of the carbon materials are given in Figure 1.

The TEM images show that there are differences between the different carbon materials in size, shape, and structure. Most notably YP-80F differs from the rest of carbon materials as its particles are significantly smaller and seem to have a two dimensional character, i.e., they are flake-like. It is also notable that LITX 200 consists of two distinct kinds of particles, larger ( $c a$ $49 \mathrm{~nm}$ on average) and smaller ones ( $c a 9.5 \mathrm{~nm}$ on average). The image in Figure $1 \mathrm{H}$ shows BP2000 carbon deposited on the lacy carbon substrate with Nafion. The image shows that Nafion binds the carbon nanoparticles to the lacy carbon substrate enveloping them partially. The average size of the nanoparticles identified in the TEM images from different carbon samples are summarized in Table 1.

It is notable that the sizes of BP2000, Vulcan, LITX 200 and ENSACO are comparable, taking into account their standard deviations. PBX51, and particularly YP-80F are notably smaller in size, while C-Nergy contains larger particles, as observed in TEM micrographs. In order to determine the surface area and porosity we performed $\mathrm{N}_{2}$ adsorption on the carbon materials and recorded the isotherms. The results of BET surface area and t-plot fits are summarised in Table 2.

The properties of the carbon materials, both the specific surface areas and porosities, vary greatly. Comparing the size distribution with the measured surface area of the carbon materials, it is clear that the differences in the surface areas is not merely the result of different particle size 10 
(see SI3). We consider the differences are likely to a large degree due to the structure and porosity of the carbon particles.

The carbon materials, sprayed onto a gas diffusion layer (GDL) were submerged in an $\mathrm{O}_{2^{-}}$ saturated $0.1 \mathrm{M} \mathrm{HClO}_{4}$ electrolyte and a potential of $-0.2 \mathrm{~V}$ was applied. Considering the differences in their specific surface areas and the effects of catalyst loading on ORR selectivity, the faradaic efficiencies were assessed under two different conditions: (a.) one were the surface area of the carbon materials sprayed onto the GDL was the same (but the mass of carbon, and therefore, the thickness of the catalyst layer was different) - the value of $0.2 \mathrm{~m}^{2}$ was chosen, and (b.) the same mass of the material, $150 \mu \mathrm{g} \mathrm{cm}^{-2}$ was applied (with the carbon surface area differing significantly in this case (for details see SI4). The measured faradaic efficiencies of the carbon catalysts are shown in Figure 2.

Figure 2 A shows that at constant surface area YP-80F and BP2000 display the highest FE of ca $82 \%$, while other carbon materials show lower FE values, with the lowest one being only about $18 \%$ (C-Nergy). While the selectivities displayed by the BP2000 and YP-80F carbons are similar, the partial current density (normalized per geometric electrode area) of YP-80F is significantly higher, likely due to the higher specific surface area of this carbon material. The significant differences in the selectivities of these carbon materials, displayed at both the same surface area and mass loading of the carbon, are not easy to explain at first glance.

Generally, higher surface area carbons required lower loading to achieve the designated 0.2 $\mathrm{m}^{2}$, so the catalyst layer is thinner in comparison to lower surface area materials in Figure 2A, which generally favours the 2-electron process. While we showed that decreasing the loading can have a notable effect on the selectivity of carbon catalysts, this effect alone is cannot completely 
explain the differences seen in Figure 2 (see SI5). For instance, with the decrease in the loading of C-Nergy by an order of magnitude (from 1690 to $176 \mu \mathrm{g} \mathrm{cm}^{-2}$ ) the selectivity improved from $17.5 \%$ to about $32 \%$, which is significant, but still far from that displayed by the best catalysts. In order to eliminate the effects originating from the difference in loading, we have also assessed the faradaic efficiencies in the same configuration with same loading, i.e., same mass of sprayed carbon catalyst, Figure 2B. At constant mass loading BP2000 performs the best as well, followed by Vulcan, YP-80F, and PBX51. The Vulcan carbon, however displays a relatively low current density, probably due to its relatively low specific surface area $\left(234 \mathrm{~m}^{2} \mathrm{~g}^{-1}\right)$.

The electrochemical characterization of the carbon electrodes (see SI6) shows that the double-layer capacitance at constant mass determined by cyclic voltammetry and capacitance due to adsorption from electrochemical impedance spectroscopy at $-0.2 \mathrm{~V}$ scale seemingly linearly with the BET surface area of the carbon materials. This indicates that the differences in the surface areas are retained in the electrode/electrolyte interface even with the inclusion into Nafion polymer, as well as that the micropores are likely accessible for the reaction since otherwise the dependence would quickly reach a plateau since the differences in BET surface area of, e.g., ENSACO, PBX51, BP2000, and YP80F are mostly due to the micropore area, Table 2.

The faradaic efficiency at constant mass (chosen considering that PGAA/NAA is a bulk technique) are shown as a function of the total metal contents, Figure 3A, and the contents of Fe, Ni and Co, Figure 3B, of the carbon catalysts as determined by PGAA/NAA.

While it may in principle be said that good catalysts for oxygen reduction to $\mathrm{H}_{2} \mathrm{O}_{2}$ contain low amounts of metals, the correlation between metal content and selectivity is not 
straightforward. It is notable that carbons with similar selectivity can have significantly different metal contents. The contents of transition metals (see SI7) that are known to influence the selectivity for the ORR, such as Fe (21 ppm in YP-80F and PBX51, less than 10 ppm in Vulcan, C-Nergy and BP2000), Co and Ni (ppm levels in all carbons) also do not correlate with the observed selectivity trends, Figure 3B. This indicates that the metal content is likely not the only factor that determines the electrocatalytic properties of these materials for the ORR.

The amounts of $\mathrm{N}$ and $\mathrm{S}$ in the carbon materials were also determined by PGAA/NAA and were found to be significantly different for different carbon materials, as shown in Figure 4. The concentration of boron in the materials was generally very low, 1-6 ppm (see SI8 for full table). Phosphor was below detection limit in all samples.

The oxygen content could not be determined by PGAA/NAA due to the difficulty of oxygen activation (requires three subsequent neutron captures to become $\mathrm{O}^{19}$ ). In order to investigate the surface composition of the carbon materials XPS measurements were performed. Surveys in the range of $0-1350 \mathrm{eV}$ of electron binding energy (BE) displayed only the $\mathrm{C} 1 \mathrm{~s}$ and $\mathrm{O} 1 \mathrm{~s}$ peaks. The relative intensities and shapes of these peaks were, however, different for different materials. Small N1s-peaks appearing only for high N-content carbon materials but their intensity was insufficient for any meaningful analysis. The $\mathrm{C} 1 \mathrm{~s}$ peaks in the carbon material are generally deconvoluted to six different peaks (see SI9) assigned to different chemical states of the C atoms. These are assigned to the following carbon states: 1. 284.3-284.6 eV BE - aromatic structures, graphite, $\mathrm{sp}^{2}$ 2. $\sim 285.2-285.6 \mathrm{eV}$ BE - localized alternant hydrocarbon, $\mathrm{sp}^{3}$ 3. $\sim 286.1-286.3 \mathrm{eV}$ BE -OH, S-component 4. 287.3-287.8 eV BE - C=O (carbonyl, quinone) 5. $\sim 288.6-289.3 \mathrm{eV}$ BE - COOH (carboxyl), N-component 6. $\sim 290.6-291.0 \mathrm{eV} \mathrm{BE}-\pi^{*} \leftarrow \pi$ shake-up, 
carbonate[13,64-66]. The less intense O1s peaks could not be analysed to obtain reproducible information about the chemical state of the oxygen at the carbon surface.

The $\mathrm{C} 1 \mathrm{~s}$ and $\mathrm{O} 1 \mathrm{~s}$ peaks were integrated in order to estimate the ratio of the carbon and oxygen atoms at the surface using the equation: $\mathrm{N}_{\mathrm{O}} / \mathrm{N}_{\mathrm{C}}=\mathrm{I}_{\mathrm{O}} \cdot \mathrm{S}_{\mathrm{C}} / \mathrm{I}_{\mathrm{C}} \cdot \mathrm{S}_{\mathrm{O}}$, where $\mathrm{I}_{\mathrm{C}}$ and $\mathrm{I}_{\mathrm{O}}$ are the intensities of the peaks, and $S_{C}$ and $S_{O}$ - the relative sensitivity factors for surface carbon $(0.25)$ and oxygen (0.66) respectively[67]. The FEs of the materials as a function of their surface oxygen content, i.e., the ratio of oxygen to carbon atoms as determined from the XPS spectra are shown in Figure 5.

From Figure 5 we can conclude that surface oxygen content does not show clear correlation with the selectivity for the $\mathrm{H}_{2} \mathrm{O}_{2}$ generation. We note here that the results of surface oxygen fraction as determined by XPS for Vulcan carbon are similar to the results reported in literature, ca $0.03[13]$.

In order to investigate further the dependence of the faradaic efficiency on the $\mathrm{N}_{\mathrm{o}} / \mathrm{N}_{\mathrm{c}}$ ratio, we attempted to alter the amount of oxygen on the surface of the carbon materials. It has been shown that oxidizing and reducing agents can oxidize groups at the surface of carbon black and with a larger the surface area, the ability for electron exchange increases[68]. BP2000 was subjected to treatment at elevated temperatures $\left(900^{\circ} \mathrm{C}\right.$ and $1000^{\circ} \mathrm{C}$ for $\left.2 \mathrm{~h}\right)$ in an Ar-stream, oxidation in $15 \% \mathrm{H}_{2} \mathrm{O}_{2}$ for $10 \mathrm{~h}$, and ENSACO was treated at $500^{\circ} \mathrm{C}$ in an $\mathrm{H}_{2}$-stream. Liquid phase oxidation with $\mathrm{H}_{2} \mathrm{O}_{2}$ and $\mathrm{HNO}_{3}$ both resulted in the decrease of selectivity of BP2000 carbon. Gas phase oxidation of C-Nergy, improved its faradaic efficiency from 18 to $32 \%$, however it also lead to an increase in specific surface area (from 63 to $146 \mathrm{~m}^{2} \mathrm{~g}^{-1}$ ) and porosity (from $\sim$ to $0.024 \mathrm{~cm}^{3} \mathrm{~g}^{-1}$ ). The same treatment of BP2000 did not result in an improvement in the selectivity, but it had little effect on the BET parameters as well (BP was oxidized at $400^{\circ} \mathrm{C}$ 
because it burned off at higher temperatures). In the case of BP2000 both increasing the amount of surface oxygen by gas- or liquid-phase oxidation and decreasing it by heating (although some re-adsorption can be expected[69]) leads to a decrease in selectivity.

The content of other non-metals in the carbon materials was also analysed using PGAA/NAA (see SI8). The amount of hydrogen was found to be in the range of $c a$ 0.1-1 mass\%, which corresponds to approximately 1.25-11.2 atomic\%. The faradaic efficiencies and partial current density at constant surface areas correlate with the amounts of detected hydrogen surprisingly well, Figures $6 \mathrm{~A}$ and B. The partial current density for the 4-electron process remains similar, being somewhat higher for the low-surface area carbons, Figure 6C. This unexpected dependence could be explained if the hydrogen atoms were mostly located on the surface of the carbon particles.

Further analysis of the XPS peaks, namely the deconvolution of the C1s peak (see SI9) shows that the peak at $\sim 284.3 \mathrm{eV} \mathrm{BE}$ associated with aromatic and graphitic structures, and the one at $\sim 285.6 \mathrm{eV}$ BE assigned to localized alternant hydrocarbons reveal certain interesting trends. The peak at $284.3 \mathrm{eV}$ becomes less intense for carbons with higher faradaic efficiencies, Figures 6D and E, while the peak at $285.6 \mathrm{eV}$ generally increases in intensity.

This observation is indeed consistent with more hydrogen present at the surface of carbon materials as the increase of the $285.6 \mathrm{eV}$ peak indicates an increase in the aliphatic (hydrocarbon-like) character of the surface, as opposed to graphitic.

\section{Discussion}

The lowest surface area carbons (C-Nergy, LITX 200) seem to have a rather poor catalytic performance for the reaction. The role of the micropores could particularly be of great 
significance for the catalysis of the reaction. The mass transport within the micropores could be inhibited. Additionally, when the carbon powder is applied with the Nafion® polymer, Figure $1 \mathrm{H}$, many of the micropores might be inaccessible for the electrolyte. If $\mathrm{H}_{2} \mathrm{O}_{2}$ could not efficiently diffuse away from the catalyst surface, i.e. the $\mathrm{H}_{2} \mathrm{O}_{2}$ concentration in the micropores could be higher; the likelihood of it being further reduced to $\mathrm{H}_{2} \mathrm{O}$ would, therefore, be greater, thus reducing the FE. Analysing the BET data in Table 2, it is particularly interesting to note two groups of materials with similar external surface areas. The first one being BP 2000, PBX51 and ENSACO, which of which ENSACO has a significantly smaller ( $c a 3.5$ times) micropore volume. The faradaic efficiencies of these carbons are approximately 75, 66 and $62 \%$, respectively. Similarly, Vulcan and LITX 200 have similar external surface areas, but the micropore volume of Vulcan is $c a 5$ times larger. However, this does not seem to have a notable detrimental effect on the FE, which is actually higher for Vulcan carbon $(68 \%$, while it is $62 \%$ for LITX 200). In fact, surprisingly, carbons with high micropore volumes seem to be efficient for $\mathrm{H}_{2} \mathrm{O}_{2}$ generation.

In Figures $7 \mathrm{~A}$ and $\mathrm{B}$ the faradaic efficiency and partial current density for the reduction of $\mathrm{O}_{2}$ to $\mathrm{H}_{2} \mathrm{O}_{2}$ are plotted as a function of the micropore volume. Carbons with higher (ENSACO, PBX51, BP 2000 and YP-80F) microporosity, $>0.1 \mathrm{~cm}^{3} \mathrm{~g}^{-1}$, apparently display higher partial current density for $\mathrm{H}_{2} \mathrm{O}_{2}$ generation. At the same time, the presence of micropores does not seem to affect the activity for the 4-electron process. The higher amount of micropores observed for more efficient catalysts is in line with the observation that catalysts with a higher amount of defects on the surface display higher efficiency for the reaction. The number of micropores correlates with the amount of hydrogen detected by PGAA/NAA (SI9). 
The metal content of the catalyst is not the deciding factor regarding the selectivity of these catalysts towards the reaction. A number of metal-containing carbon catalysts have been developed for the ORR, i.e., for the 4-electron pathway[70,71], but also for the 2-electron one[72,73] Therefore, the chemical state of the metal atoms is likely an important factor to consider.

The high selectivity of some of the S- and N-containing catalysts towards the 2-electron pathway is surprising considering previous findings in the literature that carbons materials with significant amounts of these elements favour the formation of water[35,74,75], particularly if we take into consideration that synergetic effects of $\mathrm{N}$ and S[76] have also been observed. From Figure 4A we can see that carbons containing similar amounts of $\mathrm{N}$ can have very different selectivities for the ORR. This could be due to the fact that different nitrogen containing functionalities can have different influences on the selectivity for the ORR, as the nature of the active sites for ORR in CN-type catalysts is still controversial (compare for instance refs [75,7779]). This is in line with these findings of Biddinger and Ozkan[80] and Zhao et al. [75], that indicate that the overall nitrogen content is a poor indicator of ORR activity, and only certain types of nitrogen, e.g., on the edges of graphitic sheets promotes the 4-electron process $[81,82]$. There are only three carbons with significant sulphur content: BP2000, Vulcan and PBX51, and they showed high faradaic efficiencies. However, the difference in the FE between the best lowsulphur catalyst (YP-80F) and best sulphur containing (relatively high 10300 ppm in BP2000) is only about $9 \%$. Thus, the possible role of sulphur in the catalysis of this reaction requires further clarification. 
Carbons with a slightly higher oxygen content generally display higher faradaic efficiencies for $\mathrm{H}_{2} \mathrm{O}_{2}$ generation at constants surface area, while YP80F shows comparatively high oxygen content, Figure 5. However, carbons with similar amounts of oxygen at the surface can display significantly different faradaic efficiencies, e.g., LITX 200 and ENSACO. This could be due to the different activity, or lack thereof, and selectivity of various oxygen functionalities in the catalysis of the ORR. Another possible issue is that XPS measurements were conducted on asreceived or modified carbon materials that have not been subjected to the ORR. The state of the surface oxygen might be quite different under ORR conditions $(-0.2 \mathrm{~V}, \mathrm{pH}=1)$ and the oxygen content of as-received carbons can differ from that during the catalysis of the reaction. Strelko et al.[50] predicted that the electron-donor ability of the carbon will have a maximum, and they place it at value 4-6\% oxygen of furanic and carbonyl groups, while $\mathrm{C}=\mathrm{O}$ reduces that capability as the authors have found lower overall currents. The fact that lower temperature treatment of the carbon materials in Ref [27] leads to selectivity towards the two electron pathway, while treatment at $800^{\circ} \mathrm{C}$ leads to selectivity towards the 4-electron one since higher temperatures will result in the removal of more surface oxygen. The increased oxygen content was also found to have an influence on the hydrophilic character of the carbon materials[13,54]; it is possible that increasing the hydrophilic character of the surface could contribute to improved activity, however, after a certain hydrophilicity has been obtained, further introduction of oxygenated groups would not lead to further improvement in activity.

$\mathrm{H}_{2} \mathrm{O}_{2}$ treatment leads to an increase in acidic groups[54]. Song et al.[56] found that gaseous oxidation leads to a predominant population of quinoid, while liquid phase oxidation is leading to large amounts of surface carboxylic groups. Figueiredo et al.[83] similarly note that gas phase oxidation of the carbon increases mainly the concentration of hydroxyl and carbonyl, while 18 
liquid phase oxidation increases the concentration of carboxylic groups. Thus, there seem to be significant differences in the changes induced in carbons undergoing liquid- and gas-phase oxidation. Both liquid- and gas-phase oxidation of BP2000, as well as heating in an inert atmosphere resulted a decreased selectivity for the 2-electron process (while the surface area and porosity did not change significantly). Surprisingly, the gas phase oxidation treatment increased the surface oxygen content of C-Nergy (O/C ratio of 0.047$)$, which lead to improved selectivity for the reaction. This gas-phase oxidation procedure also induced significant changes in the surface area and porosity, which increased from 63 to $146 \mathrm{~m}^{2} \mathrm{~g}^{-1}$ and from $c a 0$ to $0.024 \mathrm{~cm}^{3} \mathrm{~g}^{-1}$, respectively. The gas phase oxidation introduced structural changes to the material, changing its porosity and introducing "defects" to the surface.

It is interesting to note that carbons that display high faradaic efficiencies at constant surface area show high hydrogen content, Figure 6 A. The explanation could be that most of the hydrogen detected using PGAA/NAA is located at the surface of carbon materials. Similarly, the partial current density for $\mathrm{H}_{2} \mathrm{O}_{2}$ generation also indicates that carbons with a higher hydrogen content are generally more active, Figure 6B. XPS results also indicate that carbons with high selectivity for the 2-electron process contain more "defect sites", in contrast to ones with lower selectivities that show a more graphitic character. A similar effect has been observed previously in alkaline media[13]. It has been shown that decreasing the graphitic nature of the carbon leads to improved redox capacity[68], in agreement with our observations.

There is likely a link between the amount of defects on the surface and microporosity. Carbons with high amounts of micropores consequentially have a larger amount of surface defects, i.e., less graphitic structures and more aliphatic-like sites. Indeed, the defects have been 
shown to have an influence even greater than the presence of foreign atoms in some cases[36]. It has also been shown that the electron transfer site on graphene sheets are the edges[84].

The results obtained in this work have significant implications for the synthesis of carbonbased catalysts for the 4-electron process. In order to improve the performance of these catalysts for ORR to water, it seems carbon materials with low microporosity are to be chosen. The introduction of heteroatoms (metals, nitrogen, oxygen, etc.) should be done with great care taking into account their chemical state when incorporated into the carbon material. The complex interactions between carbon, heteroatoms (nitrogen in particular), and possibly the adventitious metals present, along with various synergetic doping effects (e.g., $\mathrm{N}$ and $\mathrm{S}$ ) make the interpretation of their influence of particular components challenging.

\section{Conclusions}

The electrocatalytic performance of carbon materials towards the $\mathrm{O}_{2}$-reduction to $\mathrm{H}_{2} \mathrm{O}_{2}$ in acidic media depends on several factors, such as transition metal content, doping with heteroatoms and surface defects.

The determination of surface area and porosity showed a dependence of the activity for hydrogen peroxide generation on the porosity of carbon materials. The metal content is likely significant, however at levels found in these catalysts (in the order of tens of ppm) does not seem to be the determining factor. The dependence of the electrocatalytic performance on the surface oxygen content as determined by XPS shows no clear correlation. The elucidation of the role of different oxygen functionalities is necessary for the assessment the influence of surface oxygen on the electrocatalytic properties. Similarly, the chemical state of $\mathrm{N}$ and S, i.e., the presence of different functionalities and their influence on ORR selectivity requires further elucidation. 
However, we found a surprising correlation between the hydrogen content and faradaic efficiency. This result from NAA/PGAA was supported by XPS data as well, which showed that carbon materials with high faradaic efficiencies have higher contribution from the $\mathrm{C} 1 \mathrm{~s}$ peak component correlated with aliphatic-type carbon atoms, as opposed to graphitic, and an increased amount of aliphatic-like carbon sites indeed entails higher H-content on the surface of the carbon particles, as seen in PGAA/NAA measurements. This fact indicates the role of defects in the electrocatalysis of this reaction, in line with the observations from BET as microporous materials likely have more defect sites.

The assessment of the nature of the active site and the factors significant for the electrochemical oxygen reduction to $\mathrm{H}_{2} \mathrm{O}_{2}$ activity and selectivity requires further insight into the structure of the carbon materials and the chemical state of the surface.

\section{Acknowledgements}

This work was supported by a research grant (9455) from VILLUM FONDEN and the Danmarks Innovationsfond within the ProActivE project (5160-00003B). This work is based upon experiments performed at the PGAA/NAA instrument operated by FRM II at the Heinz MaierLeibnitz Zentrum (MLZ), Garching, Germany

\section{References:}

[1] R. Ciriminna, L. Albanese, F. Meneguzzo, M. Pagliaro, Hydrogen Peroxide: A Key Chemical for Today's Sustainable Development, ChemSusChem. 9 (2016) 3374-3381. doi:10.1002/cssc.201600895.

[2] G. Goor, J. Glenneberg, S. Jacobi, Hydrogen Peroxide, in: Ullmanns Encycl. Ind. Chem., 
2011: pp. 131-139. doi:10.1002/14356007.a13.

[3] B. Puertolas, A.K. Hill, T. Garcia, B. Solsona, L. Torrente-Murciano, In-situ synthesis of hydrogen peroxide in tandem with selective oxidation reactions: A mini-review, Catal. Today. 248 (2015) 115-127. doi:10.1016/j.cattod.2014.03.054.

[4] J.M. Campos-Martin, G. Blanco-Brieva, J.L.G. Fierro, Hydrogen peroxide synthesis: An outlook beyond the anthraquinone process, Angew. Chemie - Int. Ed. 45 (2006) 69626984. doi:10.1002/anie.200503779.

[5] C. Samanta, Direct synthesis of hydrogen peroxide from hydrogen and oxygen: An overview of recent developments in the process, Appl. Catal. A Gen. 350 (2008) 133-149. doi:10.1016/j.apcata.2008.07.043.

[6] D. Shores, G. Deluga, Handbook of fuell cells fundamentals, technology and applications, Wiley, New York, 2003.

[7] J.K. Edwards, G.J. Hutchings, Palladium and gold-palladium catalysts for the direct synthesis of hydrogen peroxide, Angew. Chemie - Int. Ed. 47 (2008) 9192-9198. doi:10.1002/anie.200802818.

[8] E. Pizzutilo, S.J. Freakley, S. Cherevko, S. Venkatesan, G.J. Hutchings, C.H. Liebscher, G. Dehm, K. Mayrhofer, Gold-Palladium Bimetallic Catalyst Stability: Consequences for Hydrogen Peroxide Selectivity., ACS Catal. (2017) acscatal.7b01447. doi:10.1021/acscatal.7b01447.

[9] A. Bonakdarpour, D. Esau, H. Cheng, A. Wang, E. Gyenge, D.P. Wilkinson, Preparation and electrochemical studies of metal-carbon composite catalysts for small-scale electrosynthesis of $\mathrm{H}_{2} \mathrm{O}_{2}$, Electrochim. Acta. 56 (2011) 9074-9081. doi:10.1016/j.electacta.2011.06.043. 
[10] F. Hasché, M. Oezaslan, P. Strasser, T.P. Fellinger, Electrocatalytic hydrogen peroxide formation on mesoporous non-metal nitrogen-doped carbon catalyst, J. Energy Chem. 25 (2016) 251-257. doi:10.1016/j.jechem.2016.01.024.

[11] S. Fukuzumi, Y. Yamada, K.D. Karlin, Hydrogen peroxide as a sustainable energy carrier: Electrocatalytic production of hydrogen peroxide and the fuel cell, Electrochim. Acta. 82 (2012) 493-511. doi:10.1016/j.electacta.2012.03.132.

[12] Z. Chen, S. Chen, S. Siahrostami, P. Chakthranont, C. Hahn, D. Nordlund, S. Dimosthenis, J.K. Nørskov, Z. Bao, T.F. Jaramillo, Development of a reactor with carbon catalysts for modular-scale, low-cost electrochemical generation of $\mathrm{H}_{2} \mathrm{O}_{2}$, React. Chem. Eng. 2 (2017) 239-245. doi:10.1039/C6RE00195E.

[13] A. Moraes, M.H.M.T. Assumpção, F.C. Simões, V.S. Antonin, M.R. V Lanza, P. Hammer, M.C. Santos, Surface and Catalytical effects on Treated Carbon Materials for Hydrogen Peroxide Electrogeneration, Electrocatalysis. 7 (2016) 60-69. doi:10.1007/s12678-015-0279-5.

[14] E. Brillas, F. Alcaide, P.L. Cabot, A small-scale flow alkaline fuel cell for on-site production of hydrogen peroxide, Electrochim. Acta. 48 (2002) 331-340. doi:10.1016/S0013-4686(02)00665-5.

[15] I. Yamanaka, T. Onizawa, S. Takenaka, K. Otsuka, Direct and continuous production of hydrogen peroxide with $93 \%$ selectivity using a fuel-cell system, Angew. Chemie - Int. Ed. 42 (2003) 3653-3655. doi:10.1002/anie.200351343.

[16] N. Ramaswamy, S. Mukerjee, Influence of Inner-and Outer-Sphere Electron Transfer Mechanisms during Electrocatalysis of Oxygen Reduction in Alkaline Media, J. Phys. Chem. C. 115 (2011) 18015-18026. doi:10.1021/jp204680p. 
[17] Y. Gorlin, C.-J. Chung, D. Nordlund, B.M. Clemens, T.F. Jaramillo, Mn 3 O 4 Supported on Glassy Carbon: An Active Non-Precious Metal Catalyst for the Oxygen Reduction Reaction, ACS Catal. 2 (2012) 2687-2694. doi:10.1021/cs3004352.

[18] I. Yamanaka, T. Murayama, Neutral $\mathrm{H}_{2} \mathrm{O}_{2}$ synthesis by electrolysis of water and $\mathrm{O}_{2}$, Angew. Chemie - Int. Ed. 47 (2008) 1900-1902. doi:10.1002/anie.200704431.

[19] T. Murayama, I. Yamanaka, Electrosynthesis of neutral $\mathrm{H}_{2} \mathrm{O}_{2}$ solution from $\mathrm{O}_{2}$ and water at a mixed carbon cathode using an exposed solid-polymer-electrolyte electrolysis cell, J. Phys. Chem. C. 115 (2011) 5792-5799. doi:10.1021/jp1109702.

[20] I. Yamanaka, S. Tazawa, T. Murayama, T. Iwasaki, S. Takenaka, Catalytic synthesis of neutral hydrogen peroxide at a $\mathrm{CoN}_{2} \mathrm{C}_{\mathrm{x}}$ Cathode of a Polymer Electrolyte Membrane Fuel Cell (PEMFC), ChemSusChem. 3 (2010) 59-62. doi:10.1002/cssc.200900246.

[21] J.R. Varcoe, P. Atanassov, D.R. Dekel, A.M. Herring, M.A. Hickner, P.A. Kohl, A.R. Kucernak, W.E. Mustain, K. Nijmeijer, K. Scott, T. Xu, L. Zhuang, Anion-exchange membranes in electrochemical energy systems, Energy Environ. Sci. 7 (2014) 3135-3191. doi:10.1039/C4EE01303D.

[22] S. Siahrostami, A. Verdaguer-Casadevall, M. Karamad, D. Deiana, P. Malacrida, B. Wickman, M. Escudero-Escribano, E. a Paoli, R. Frydendal, T.W. Hansen, I. Chorkendorff, I.E.L.S. Stephens, I.E. Stephens, J. Rossmeisl, Enabling direct H2O2 production through rational electrocatalyst design., Nat. Mater. 12 (2013) 1137-43. doi:10.1038/nmat3795.

[23] A. Verdaguer-Casadevall, D. Deiana, M. Karamad, S. Siahrostami, P. Malacrida, T.W. Hansen, J. Rossmeisl, I. Chorkendorff, I.E.L. Stephens, Trends in the electrochemical synthesis of $\mathrm{H} 2 \mathrm{O} 2$ : Enhancing activity and selectivity by electrocatalytic site engineering, 
Nano Lett. 14 (2014) 1603-1608. doi:10.1021/nl500037x.

[24] J.S. Jirkovský, I. Panas, E. Ahlberg, M. Halasa, S. Romani, D.J. Schiffrin, Single atom hot-spots at $\mathrm{Au}-\mathrm{Pd}$ nanoalloys for electrocatalytic $\mathrm{H}_{2} \mathrm{O}_{2}$ production, J. Am. Chem. Soc. 133 (2011) 19432-19441. doi:10.1021/ja206477z.

[25] S. Yang, J. Kim, Y.J. Tak, A. Soon, H. Lee, Single-Atom Catalyst of Platinum Supported on Titanium Nitride for Selective Electrochemical Reactions, Angew. Chem. Int. Ed., 55(6) (2016) 2058-2062.

[26] J. Park, Y. Nabae, T. Hayakawa, M. Kakimoto, Highly Selective Two-Electron Oxygen Reduction Catalyzed by Mesoporous Nitrogen-Doped Carbon Highly Selective TwoElectron Oxygen Reduction Catalyzed by Mes- oporous Nitrogen-Doped Carbon, ACS Catal. 4 (2014) 3749-3754. doi:10.1021/cs5008206.

[27] Y.H. Lee, F. Li, K.H. Chang, C.C. Hu, T. Ohsaka, Novel synthesis of N-doped porous carbons from collagen for electrocatalytic production of $\mathrm{H}_{2} \mathrm{O}_{2}$, Appl. Catal. B Environ. 126 (2012) 208-214. doi:10.1016/j.apcatb.2012.06.031.

[28] T.P. Fellinger, F. Hasché, P. Strasser, M. Antonietti, Mesoporous nitrogen-doped carbon for the electrocatalytic synthesis of hydrogen peroxide, J. Am. Chem. Soc. 134 (2012) 4072-4075. doi:10.1021/ja300038p.

[29] J. Masa, W. Xia, M. Muhler, W. Schuhmann, On the Role of Metals in Nitrogen-Doped Carbon Electrocatalysts for Oxygen Reduction, Angew. Chemie - Int. Ed. 54 (2015) 10102-10120. doi:10.1002/anie.201500569.

[30] K. Gong, F. Du, Z. Xia, M. Durstock, L. Dai, Nitrogen-Doped Carbon Nanotube Arrays with High Electrocatalytic Activity for Oxygen Reduction., Science. 323 (2009) 760-764. doi:10.1126/science.1168049. 
[31] K.R. Lee, K.U. Lee, J.W. Lee, B.T. Ahn, S.I. Woo, Electrochemical oxygen reduction on nitrogen doped graphene sheets in acid media, Electrochem. Commun. 12 (2010) 10521055. doi:10.1016/j.elecom.2010.05.023.

[32] L. Yang, S. Jiang, Y. Zhao, L. Zhu, S. Chen, X. Wang, Q. Wu, J. Ma, Y. Ma, Z. Hu, Boron-Doped Carbon Nanotubes as Metal-Free Electrocatalysts for the Oxygen Reduction Reaction, Angew. Chemie. 123 (2011) 7270-7273. doi:10.1002/ange.201101287.

[33] Z.W. Liu, F. Peng, H.J. Wang, H. Yu, W.X. Zheng, J. Yang, Phosphorus-doped graphite layers with high electrocatalytic activity for the $\mathrm{O}_{2}$ reduction in an alkaline medium, Angew. Chemie - Int. Ed. 50 (2011) 3257-3261. doi:10.1002/anie.201006768.

[34] W. Kiciński, M. Szala, M. Bystrzejewski, Sulfur-doped porous carbons: Synthesis and applications, Carbon N. Y. 68 (2014) 1-32. doi:10.1016/j.carbon.2013.11.004.

[35] H. Wang, X. Bo, Y. Zhang, L. Guo, Sulfur-doped ordered mesoporous carbon with high electrocatalytic activity for oxygen reduction, Electrochim. Acta. 108 (2013) 404-411. doi:10.1016/j.electacta.2013.06.133.

[36] D. Yan, Y. Li, J. Huo, R. Chen, L. Dai, S. Wang, Defect Chemistry of Nonprecious-Metal Electrocatalysts for Oxygen Reactions, Adv. Mater. 1606459 (2017) 1606459. doi:10.1002/adma.201606459.

[37] G. Zhong, H. Wang, H. Yu, F. Peng, The effect of edge carbon of carbon nanotubes on the electrocatalytic performance of oxygen reduction reaction, Electrochem. Commun. 40 (2014) 5-8. doi:10.1016/j.elecom.2013.12.017.

[38] A. Shen, Y. Zou, Q. Wang, R.A.W. Dryfe, X. Huang, S. Dou, L. Dai, S. Wang, Oxygen Reduction Reaction in a Droplet on Graphite: Direct Evidence that the Edge is More Active than the Basal Plane., Angew. Chem. Int. Ed. Engl. 53 (2014) 10804-8. 
http://www.ncbi.nlm.nih.gov/pubmed/25124986 (accessed August 18, 2014).

[39] C. Médard, M. Lefèvre, J.P. Dodelet, F. Jaouen, G. Lindbergh, Oxygen reduction by Febased catalysts in PEM fuel cell conditions: Activity and selectivity of the catalysts obtained with two Fe precursors and various carbon supports, Electrochim. Acta. 51 (2006) 3202-3213. doi:10.1016/j.electacta.2005.09.012.

[40] C.H. Choi, W.S. Choi, O. Kasian, A.K. Mechler, M.T. Sougrati, S. Brüller, K. Strickland, Q. Jia, S. Mukerjee, K.J.J. Mayrhofer, F. Jaouen, Unraveling the Nature of Sites Active toward Hydrogen Peroxide Reduction in Fe-N-C Catalysts, Angew. Chemie - Int. Ed. 56 (2017) 8809-8812. doi:10.1002/anie.201704356.

[41] M. Campos, W. Siriwatcharapiboon, R.J. Potter, S.L. Horswell, Selectivity of cobaltbased catalysts towards hydrogen peroxide formation during the reduction of oxygen, Catal. Today. 202 (2013) 135-143. doi:10.1016/j.cattod.2012.05.015.

[42] J. Masa, A. Zhao, W. Xia, Z. Sun, B. Mei, M. Muhler, W. Schuhmann, Trace metal residues promote the activity of supposedly metal-free nitrogen-modified carbon catalysts for the oxygen reduction reaction, Electrochem. Commun. 34 (2013) 113-116. doi:10.1016/j.elecom.2013.05.032.

[43] M. Pumera, Y. Miyahara, What amount of metallic impurities in carbon nanotubes is small enough not to dominate their redox properties?, Nanoscale. 1 (2009) 260-5. doi:10.1039/b9nr00071b.

[44] E. Yeager, Electrocatalysts for $\mathrm{O}_{2}$ reduction, Electrochim. Acta. 29 (1984) 1527-1537. doi:10.1016/0013-4686(84)85006-9.

[45] K. Wiesener, $\mathrm{N}_{4}$-chelates as electrocatalyst for cathodic oxygen reduction, Electrochim. Acta. 31 (1986) 1073-1078. doi:10.1016/0013-4686(86)80022-6. 
[46] Ralph H. Petrucci; William S Harwood; Geoff E Herring; Jeffry Madura, General Chemistry: Principles and Modern Application, 9th editio, Prentice Hall, New York, 2007.

[47] Y. Jiao, Y. Zheng, M. Jaroniec, S.Z. Qiao, Origin of the electrocatalytic oxygen reduction activity of graphene-based catalysts: A roadmap to achieve the best performance, J. Am. Chem. Soc. 136 (2014) 4394-4403. doi:10.1021/ja500432h.

[48] N. Daems, X. Sheng, I.F.J. Vankelecom, P.P. Pescarmona, Metal-free doped carbon materials as electrocatalysts for the oxygen reduction reaction, J. Mater. Chem. A. 2 (2014) 4085-4110. doi:10.1039/C3TA14043A.

[49] J. Zhang, L. Dai, Heteroatom-Doped Graphitic Carbon Catalysts for Efficient Electrocatalysis of Oxygen Reduction Reaction, ACS Catal. 5 (2015) 7244-7253. doi:10.1021/acscatal.5b01563.

[50] V. V. Strelko, N.T. Kartel, I.N. Dukhno, V.S. Kuts, R.B. Clarkson, B.M. Odintsov, Mechanism of reductive oxygen adsorption on active carbons with various surface chemistry, Surf. Sci. 548 (2004) 281-290. doi:10.1016/j.susc.2003.11.012.

[51] D. Pantea, H. Darmstadt, S. Kaliaguine, L. Sümmchen, C. Roy, Electrical conductivity of thermal carbon blacks: Influence of surface chemistry, Carbon N. Y. 39 (2001) 11471158. doi:10.1016/S0008-6223(00)00239-6.

[52] F. Rodriguez-Reinoso, M. Molina-Sabio, M. a. Munecas, Effect of Microporosity and Oxygen Surface Groups of Activated Carbon in the Adsorption of Molecules of Different Polarity, J. Phys. Chem. 96 (1992) 2707-2713. doi:10.1021/j100185a056.

[53] A. Swiatkowski, M. Pakula, S. Biniak, M. Walczyk, Influence of the surface chemistry of modified activated carbon on its electrochemical behaviour in the presence of lead(II) ions, Carbon N. Y. 42 (2004) 3057-3069. doi:10.1016/j.carbon.2004.06.043. 
[54] F. Rodríguez-Reinoso, The role of carbon materials in heterogeneous catalysis, Carbon. 36 (1998) 159-175. doi:10.1016/S0008-6223(97)00173-5.

[55] A.B. Dongil, L. Pastor-Pérez, J.L.G. Fierro, N. Escalona, A. Sepúlveda-Escribano, Effect of the surface oxidation of carbon nanotubes on the selective cyclization of citronellal, Appl. Catal. A Gen. 524 (2016) 25-31. doi:10.1016/j.apcata.2016.05.021.

[56] W. Song, L. Yu, X. Xie, Z. Hao, M. Sun, H. Wen, Y. Li, Effect of textual features and surface properties of activated carbon on the production of hydrogen peroxide from hydroxylamine oxidation, RSC Adv. 7 (2017) 25305-25313. doi:10.1039/C7RA02003A.

[57] W. Song, J. Li, J. Liu, W. Shen, Production of hydrogen peroxide by the reaction of hydroxylamine and molecular oxygen over activated carbons, Catal. Commun. 9 (2008) 831-836. doi:10.1016/j.catcom.2007.09.006.

[58] I. Velo-Gala, J.J. López-Peñalver, M. Sánchez-Polo, J. Rivera-Utrilla, Role of activated carbon surface chemistry in its photocatalytic activity and the generation of oxidant radicals under UV or solar radiation, Appl. Catal. B Environ. 207 (2017) 412-423. doi:10.1016/j.apcatb.2017.02.028.

[59] B.K. A. Schneider, L. Colmenares, Y. E. Seidel, Z. Jusys, B. Wickman, R. Jürgen Behm, Transport effects in the oxygen reduction reaction on nanostructured, planar glassy carbon supported Pt/GC model electrodes, Phys. Chem. Chem. Phys. 10 (2008) 1931-1943. doi:10.1039/B719775F.

[60] B.K. Y. E. Seidel, A. Schneider, Z. Jusys, B. Wickman, R.J. Behm, Mesoscopic mass transport effects in electrocatalytic processes, Faraday Discuss. 140 (2008) 167-184. doi:10.1039/b806437g.

[61] Z. Révay, Determining elemental composition using prompt $\gamma$ activation analysis, Anal. 
Chem. 81 (2009) 6851-6859. doi:10.1021/ac9011705.

[62] Z. Révay, PGAA : Prompt gamma and in-beam neutron activation analysis facility, J. Large-Scale Res. Facil. 1 (2015) 19-21. doi:10.17815/jlsrf-1-46.

[63] V. Čolić, J. Tymoczko, A. Maljusch, A. Ganassin, W. Schuhmann, A.S. Bandarenka, Experimental Aspects in Benchmarking of the Electrocatalytic Activity. ChemElectroChem. 2 (2015) 143-149. DOI: 10.1002/celc.201402295

[64] R. Gusmao, Z. Sofer, M. Novacek, M. Pumera, Contrasts between Mild and Harsh Oxidation of Carbon Nanotubes in terms of their Properties and Electrochemical Performance, ChemElectroChem. 3 (2016) 1713-1719. doi:10.1002/celc.201600082.

[65] M. P. Araújo, O.S.G. P. Soares, A.J. S. Fernandes, M.F. R. Pereira, C. Freire, Tuning the surface chemistry of graphene flakes: new strategies for selective oxidation, RSC Adv. 7 (2017) 14290-14301. doi:10.1039/C6RA28868E.

[66] C. Moreno-Castilla, M.. López-Ramón, F. Carrasco-Marín, M. V Lopez-Ramon, F. Carrasco-Marin, Changes in surface chemistry of activated carbons by wet oxidation, Carbon N. Y. 38 (2000) 1995-2001. doi:Doi 10.1016/S0008-6223(00)00048-8.

[67] C.D. Wagner, L.E. Davis, M. V Zeller, J.A. Taylor, R.H. Raymond, L.H. Gale, Empirical atomic sensitivity factors for quantitative analysis by electron spectroscopy for chemical analysis, Surf. Interface Anal. 3 (1981) 211-225. doi:10.1002/sia.740030506.

[68] S. Goeringer, N.R. De Tacconi, C.R. Chenthamarakshan, K. Rajeshwar, W.A. Wampler, Redox characterization of furnace carbon black surfaces, Carbon N. Y. 39 (2001) 515522. doi:10.1016/S0008-6223(00)00170-6.

[69] J.A. Menendez, J. Phillips, B. Xia, L.R. Radovic, On the modification and characterization of chemical surface properties of activated carbon: In the search of carbons with stable 
basic properties, Langmuir. 12 (1996) 4404-4410. doi:10.1021/la9602022.

[70] M. Lefèvre, J.P. Dodelet, Fe-based catalysts for the reduction of oxygen in polymer electrolyte membrane fuel cell conditions: Determination of the amount of peroxide released during electroreduction and its influence on the stability of the catalysts, Electrochim. Acta. 48 (2003) 2749-2760. doi:10.1016/S0013-4686(03)00393-1.

[71] F. Jaouen, J.P. Dodelet, Average turn-over frequency of $\mathrm{O}_{2}$ electro-reduction for Fe/N/C and Co/N/C catalysts in PEFCs, Electrochim. Acta. 52 (2007) 5975-5984. doi:10.1016/j.electacta.2007.03.045.

[72] S. Marcotte, D. Villers, N. Guillet, L. Roué, J.P. Dodelet, Electroreduction of oxygen on Co-based catalysts: Determination of the parameters affecting the two-electron transfer reaction in an acid medium, Electrochim. Acta. 50 (2004) 179-188. doi:10.1016/j.electacta.2004.07.029.

[73] Tim S. Olson, Svitlana Pylypenko, Julia E. Fulghum, and Plamen Atanassov*, Bifunctional Oxygen Reduction Reaction Mechanism on Non-Platinum Catalysts Derived from Pyrolyzed Porphyrins, J. Electrochem. Soc. 157 (2010) B54-B63. doi:10.1149/1.3248003.

[74] W. Xia, J. Masa, M. Bron, W. Schuhmann, M. Muhler, Highly active metal-free nitrogencontaining carbon catalysts for oxygen reduction synthesized by thermal treatment of polypyridine-carbon black mixtures, Electrochem. Commun. 13 (2011) 593-596. doi:10.1016/j.elecom.2011.03.018.

[75] A. Zhao, J. Masa, M. Muhler, W. Schuhmann, W. Xia, N-doped carbon synthesized from $\mathrm{N}$-containing polymers as metal-free catalysts for the oxygen reduction under alkaline conditions, Electrochim. Acta. 98 (2013) 139-145. doi:10.1016/j.electacta.2013.03.043. 
[76] S. Bag, B. Mondal, A.K. Das, C.R. Raj, Nitrogen and sulfur dual-doped reduced graphene oxide: Synergistic effect of dopants towards oxygen reduction reaction, Electrochim. Acta. 163 (2015) 16-23. doi:10.1016/j.electacta.2015.02.130.

[77] T. Xing, Y. Zheng, L.H. Li, B.C.C. Cowie, D. Gunzelmann, S.Z. Qiao, S. Huang, Y. Chen, N.M. Graphene, T. Xing, Y. Zheng, L.H. Li, B.C.C. Cowie, D. Gunzelmann, S.Z. Qiao, Observation of Active Sites for Oxygen Reduction Reaction on, ACS Nano. 8 (2014) 1-5. doi:10.1021/nn501506p.

[78] C.V. Rao, C.R. Cabrera, Y. Ishikawa, In search of the active site in nitrogen-doped carbon nanotube electrodes for the oxygen reduction reaction, J. Phys. Chem. Lett. 1 (2010) 2622-2627. doi:10.1021/jz100971v.

[79] L. Lai, J.R. Potts, D. Zhan, L. Wang, C.K. Poh, C. Tang, H. Gong, Z. Shen, J. Lin, R.S. Ruoff, Exploration of the active center structure of nitrogen-doped graphene-based catalysts for oxygen reduction reaction, Energy Environ. Sci. 5 (2012) 7936. doi:10.1039/c2ee21802j.

[80] E.J. Biddinger, U.S. Ozkan, Role of graphitic edge plane exposure in carbon nanostructures for oxygen reduction reaction, J. Phys. Chem. C. 114 (2010) 15306-15314. doi:10.1021/jp104074t.

[81] X. Fu, J. Jin, Y. Liu, Z. Wei, F. Pan, J. Zhang, Efficient oxygen reduction electrocatalyst based on edge-nitrogen-rich graphene nanoplatelets: Toward a large-scale synthesis, ACS Appl. Mater. Interfaces. 6 (2014) 3930-3936. doi:10.1021/am405130w.

[82] R. Silva, J. Al-Sharab, T. Asefa, Edge-plane-rich nitrogen-doped carbon nanoneedles and efficient metal-free electrocatalysts, Angew. Chemie - Int. Ed. 51 (2012) 7171-7175. doi:10.1002/anie.201201742. 
[83] J.. Figueiredo, M.F.. Pereira, M.M.. Freitas, J.J.. Órfão, Modification of the surface chemistry of activated carbons, Carbon N. Y. 37 (1999) 1379-1389. doi:10.1016/S00086223(98)00333-9.

[84] P.M. Hallam, C.E. Banks, Quantifying the electron transfer sites of graphene, Electrochem. Commun. 13 (2011) 8-11. doi:10.1016/j.elecom.2010.10.030.

\section{Figure captions:}

Figure 1: TEM images of (A) YP-80F (B) BP2000 (C) PBX51 (D) LITX 200 (E) Vulcan (F) ENSACO (G) C-Nergy (H) BP2000 in Nafion ${ }^{\circledR}$ polymer. Magnification: A-G: x145000, H: $\mathrm{x} 15000$.

Figure 2: The faradaic efficiencies of different carbon materials for oxygen reduction to $\mathrm{H}_{2} \mathrm{O}_{2}$ in $\mathrm{O}_{2}$-sat $0.1 \mathrm{M} \mathrm{HClO}_{4}$ at $-0.2 \mathrm{~V}$ measured in the three-electrode setup (A) with a constant surface area of the sprayed carbon material of $c a 0.2 \mathrm{~m}^{2}$ (B) constant mass of deposited carbon of 150 $\mu \mathrm{g} \mathrm{cm}^{-2}$. Black triangles show the total current density, while red triangles represent the partial current density for $\mathrm{H}_{2} \mathrm{O}_{2}$ generation. The currents have been normalized per geometric electrode surface area.

Figure 3: The faradaic efficiency (at the same mass of carbon deposited) for $\mathrm{H}_{2} \mathrm{O}_{2}$ production by oxygen reduction in $\mathrm{O}_{2}$-sat. $0.1 \mathrm{M} \mathrm{HClO}_{4}$ at $-0.2 \mathrm{~V}$ plotted versus the (A) total metal (excluding alkali and alkaline earth metals) content (B) Fe, Co, and Ni content, determined by PGAA/NAA. Figure 4: The faradaic efficiencies (at constant mass) for $\mathrm{H}_{2} \mathrm{O}_{2}$ generation by ORR as functions of the (A) nitrogen and (B) sulphur content determined by PGAA/NAA.

Figure 5: The dependence of the faradaic efficiency (at constant surface area) for oxygen reduction to $\mathrm{H}_{2} \mathrm{O}_{2}$ in $\mathrm{O}_{2}$-sat. $0.1 \mathrm{M} \mathrm{HClO}_{4}$ at $-0.2 \mathrm{~V}$ vs. RHE on the $\mathrm{O} / \mathrm{C}$ atomic ratio on the 33 
surface of the carbon materials as determined from XPS data by the integration of the O1s and C1s peaks.

Figure 6: (A) The faradaic efficiencies at constant surface area of the carbon, (B) partial current density normalized per geometric surface area for $\mathrm{H}_{2} \mathrm{O}_{2}$ generation, and (C) partial current density normalized per geometric surface area for the 4-electron process plotted versus the hydrogen content of carbon materials as determined by PGAA/NAA. (D) The faradaic efficiency at constant surface area plotted versus the percentage of the $\mathrm{C} 1 \mathrm{~s}$ counts associated with the particular XPS peak (\% of counts), $284.6 \mathrm{eV}$ (red shapes) - assigned to graphitic or aromatic carbon and $285.7 \mathrm{eV}$ (blue shapes) assigned to aliphatic or edge C-C and (E) the ratio of the graphitic $(284.6 \mathrm{eV})$ and aliphatic "defect" counts $(285.7 \mathrm{eV})$.

Figure 7: The (A) faradaic efficiency (at constant mass) (B) Partial current density for $\mathrm{O}_{2}$ reduction to $\mathrm{H}_{2} \mathrm{O}_{2}$ (C) 4-electron ORR as a function of the micropore volume determined by the $\mathrm{N}_{2}$ adsorption t-plot method. 
Table 1: Statistics of the identified nanoparticles in different carbon samples. The number of individual identified particles was 100.

\begin{tabular}{|c|c|c|c|c|}
\hline $\begin{array}{c}\text { Carbon } \\
\text { material }\end{array}$ & $\begin{array}{c}\text { Average size } \\
/ \mathbf{n m}\end{array}$ & $\begin{array}{c}\text { Standard } \\
\text { deviation } \\
/ \mathbf{n m}\end{array}$ & $\begin{array}{c}\text { Size range } \\
/ \mathbf{n m}\end{array}$ & $\begin{array}{c}\text { Median } \\
/ \mathbf{n m}\end{array}$ \\
\hline YP-80F & 9.3 & \pm 7.7 & $2-39$ & 6.0 \\
\hline PBX51 & 13.3 & \pm 4.2 & $6-34$ & 12.8 \\
\hline BP2000 & 21.3 & \pm 10.6 & $5-55$ & 19.9 \\
\hline Vulcan & 26.9 & \pm 14 & $6-65$ & 23.8 \\
\hline LITX 200 & 27.2 & \pm 15.8 & $9-84$ & 22.8 \\
\hline ENSACO & 30.0 & \pm 8.8 & $12-55$ & 29.8 \\
\hline C-Nergy & 42.2 & \pm 15.5 & $17-96$ & 41.8 \\
\hline
\end{tabular}




\begin{tabular}{|c|c|c|c|}
\hline \multicolumn{4}{|c|}{ Table 2: Results of the BET measurements on the carbon materials } \\
\hline Carbon material & $\begin{array}{c}\text { BET Surface area } \\
/ \mathbf{m}^{\mathbf{2}} \mathbf{g}^{-\mathbf{1}}\end{array}$ & $\begin{array}{c}\text { t-plot external } \\
\text { surface area } \\
/ \mathbf{m}^{\mathbf{2}} \mathbf{g}^{-\mathbf{1}}\end{array}$ & $\begin{array}{c}\text { t-plot micropore } \\
\text { volume } \\
/ \mathbf{c m}^{\mathbf{3}} \mathbf{g}^{-1}\end{array}$ \\
\hline YP-80F & 2330 & 220 & 1.00 \\
\hline BP2000 & 1580 & 537 & 0.479 \\
\hline PBX51 & 1490 & 556 & 0.422 \\
\hline ENSACO & 790 & 509 & 0.127 \\
\hline Vulcan & 234 & 125 & 0.056 \\
\hline LITX 200 & 159 & 134 & 0.012 \\
\hline C-NERGY & 63 & 64 & 0.0001 \\
\hline
\end{tabular}



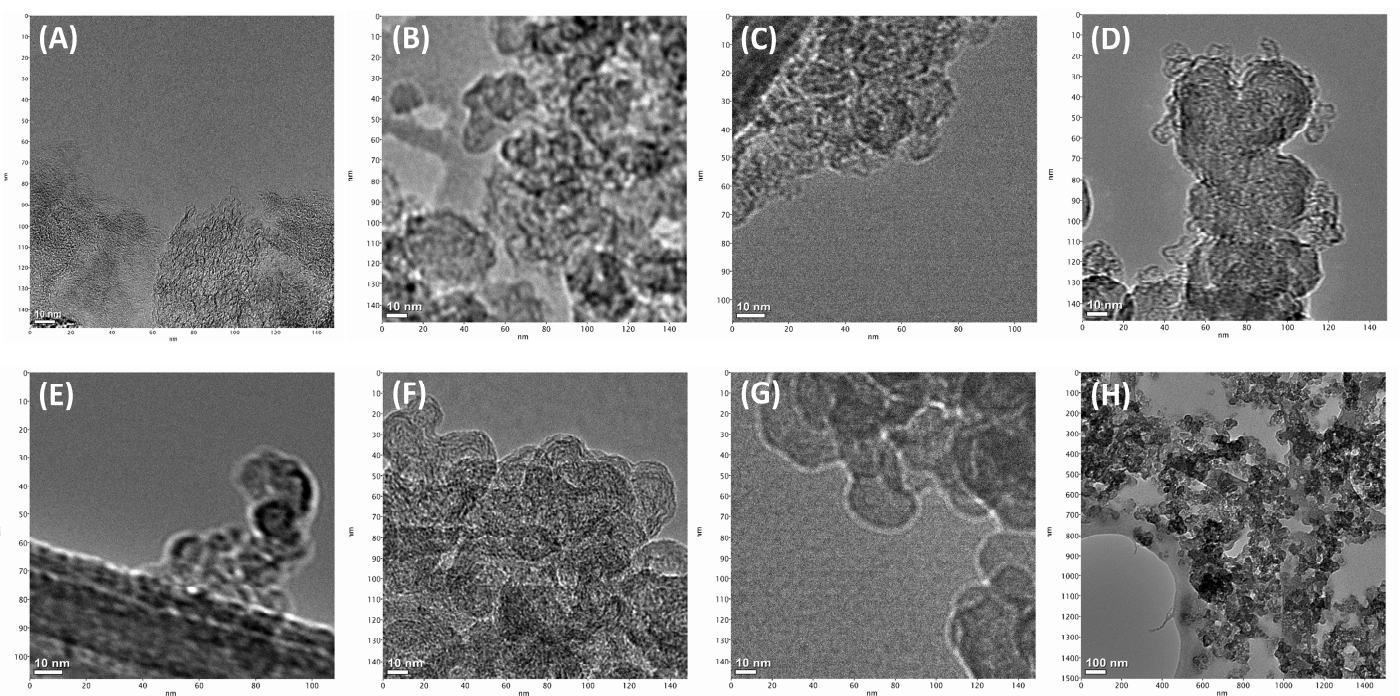


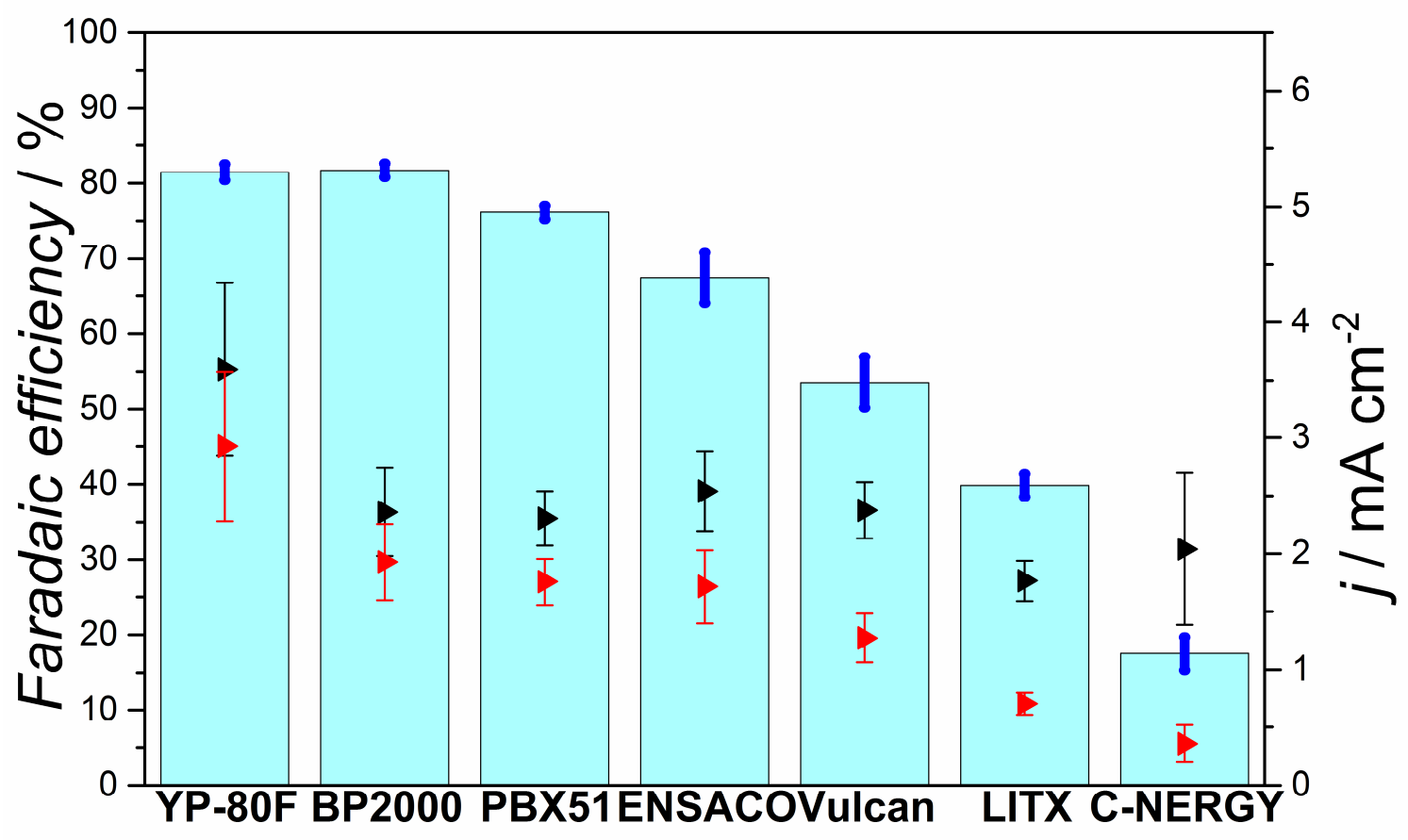




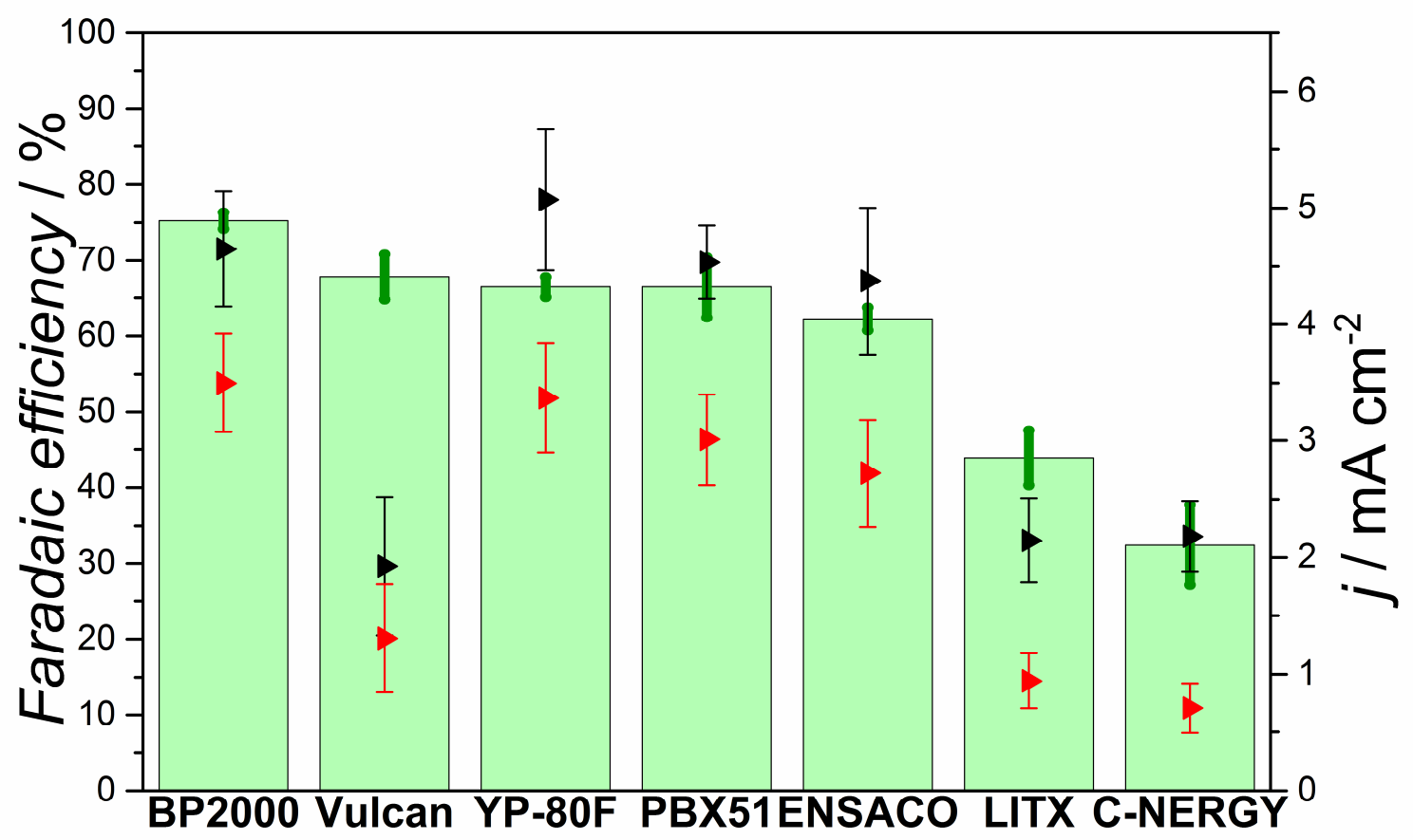




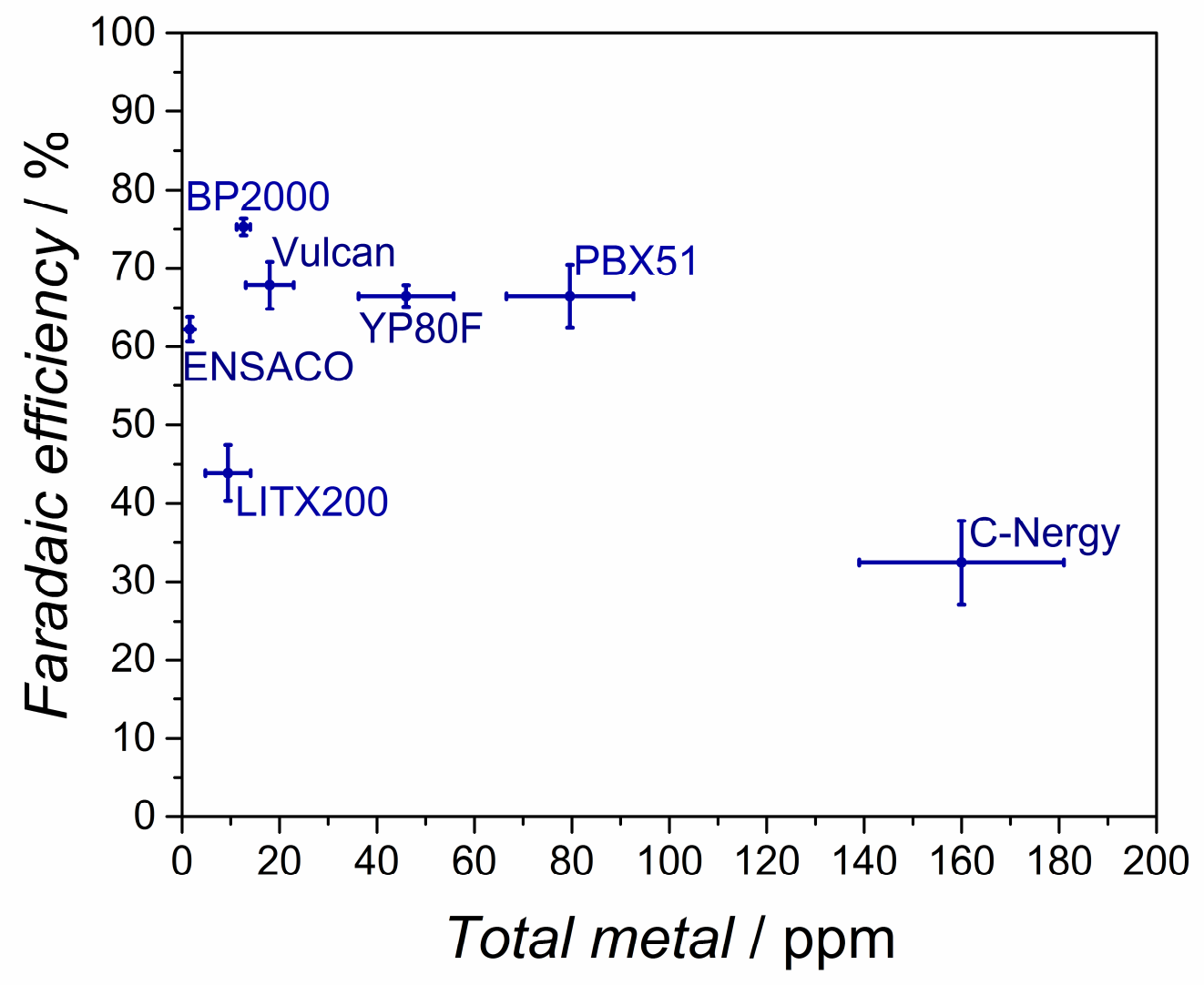




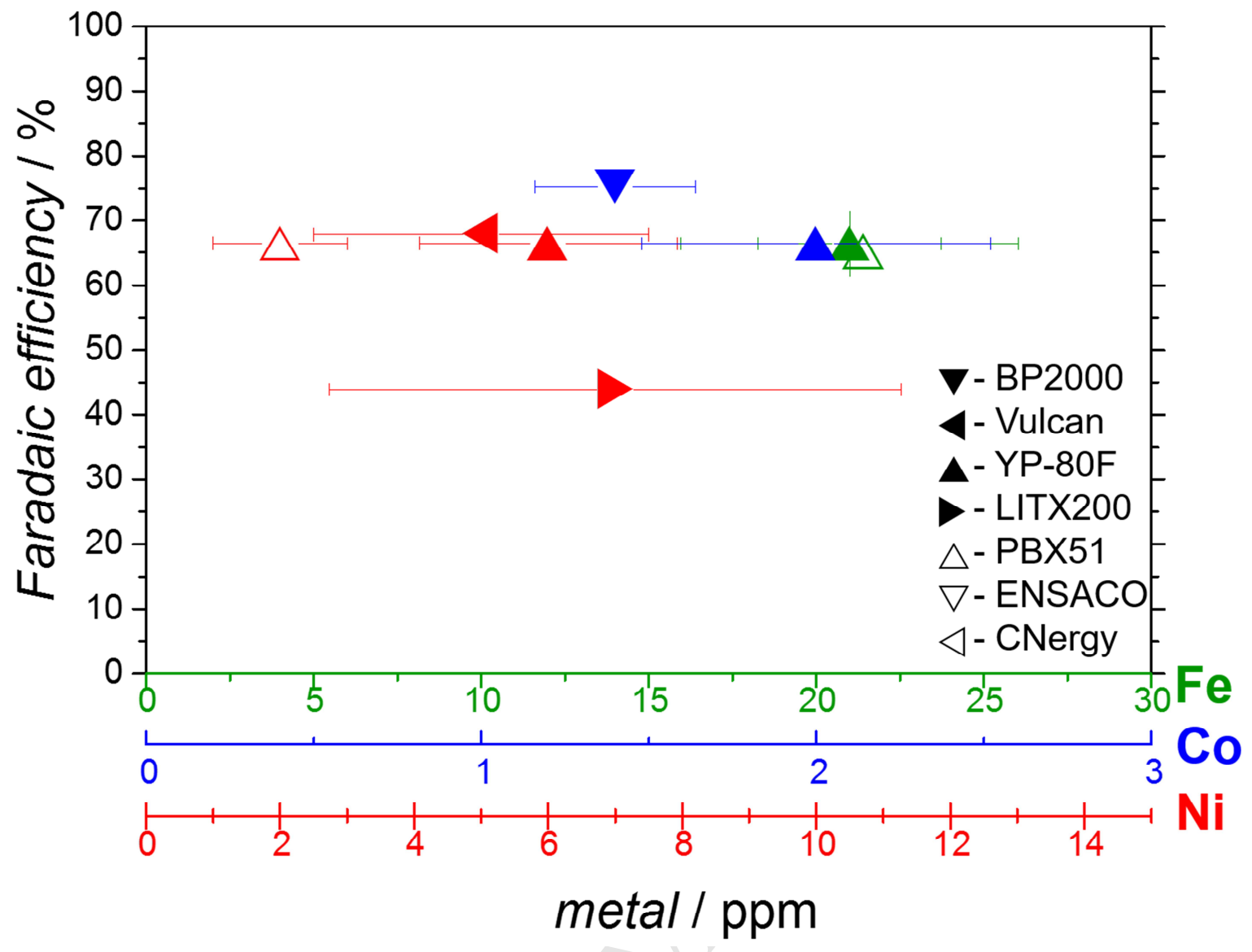




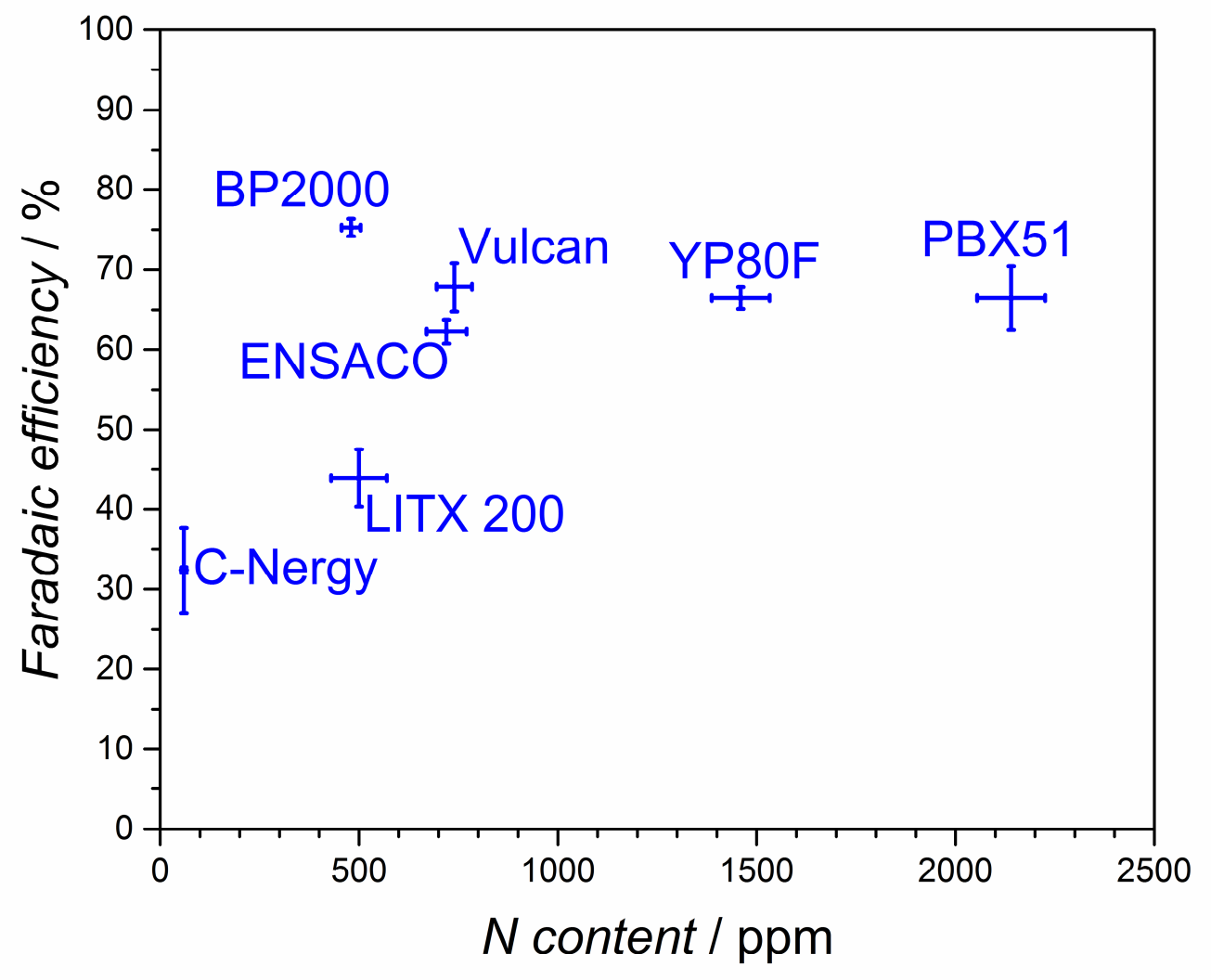




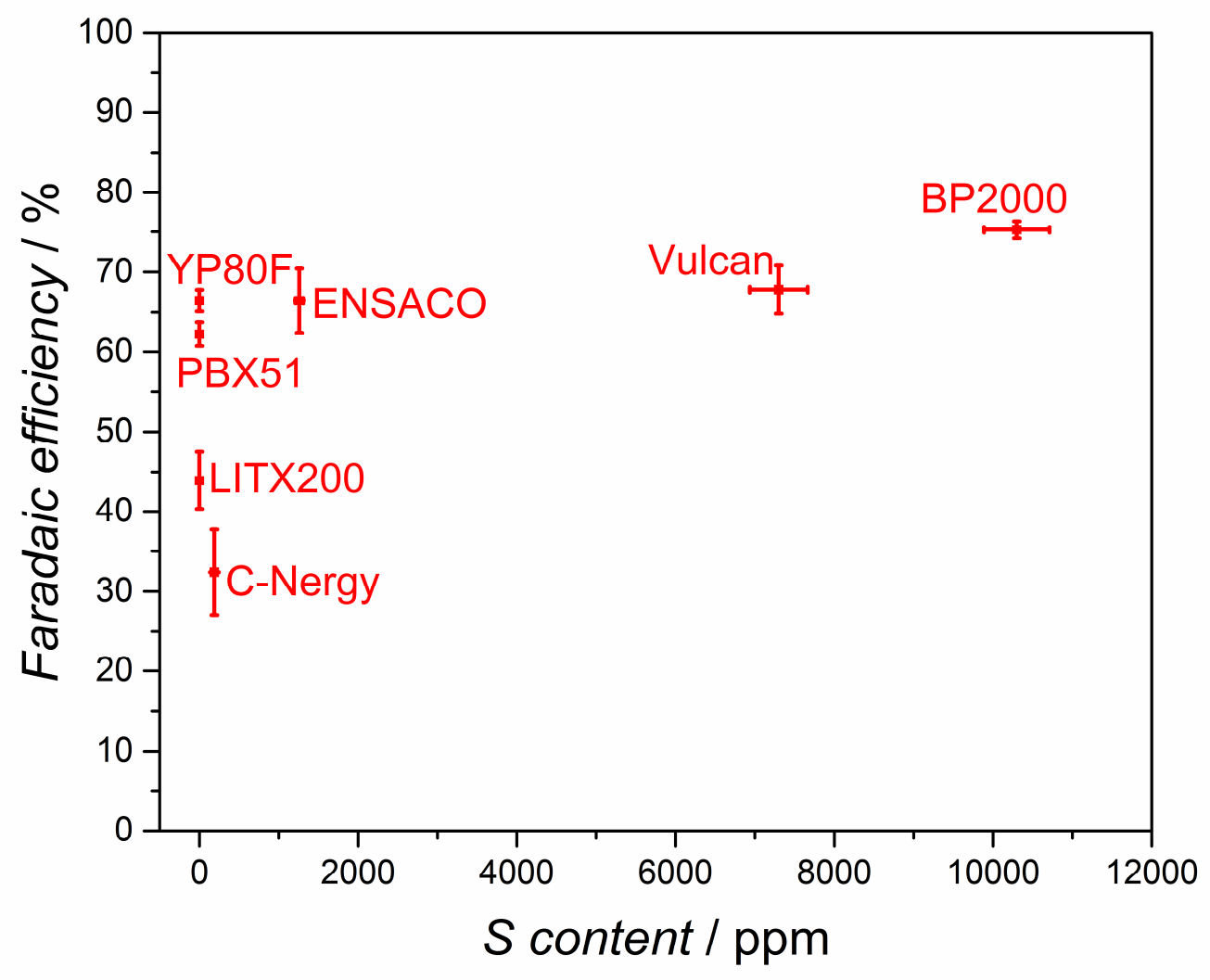




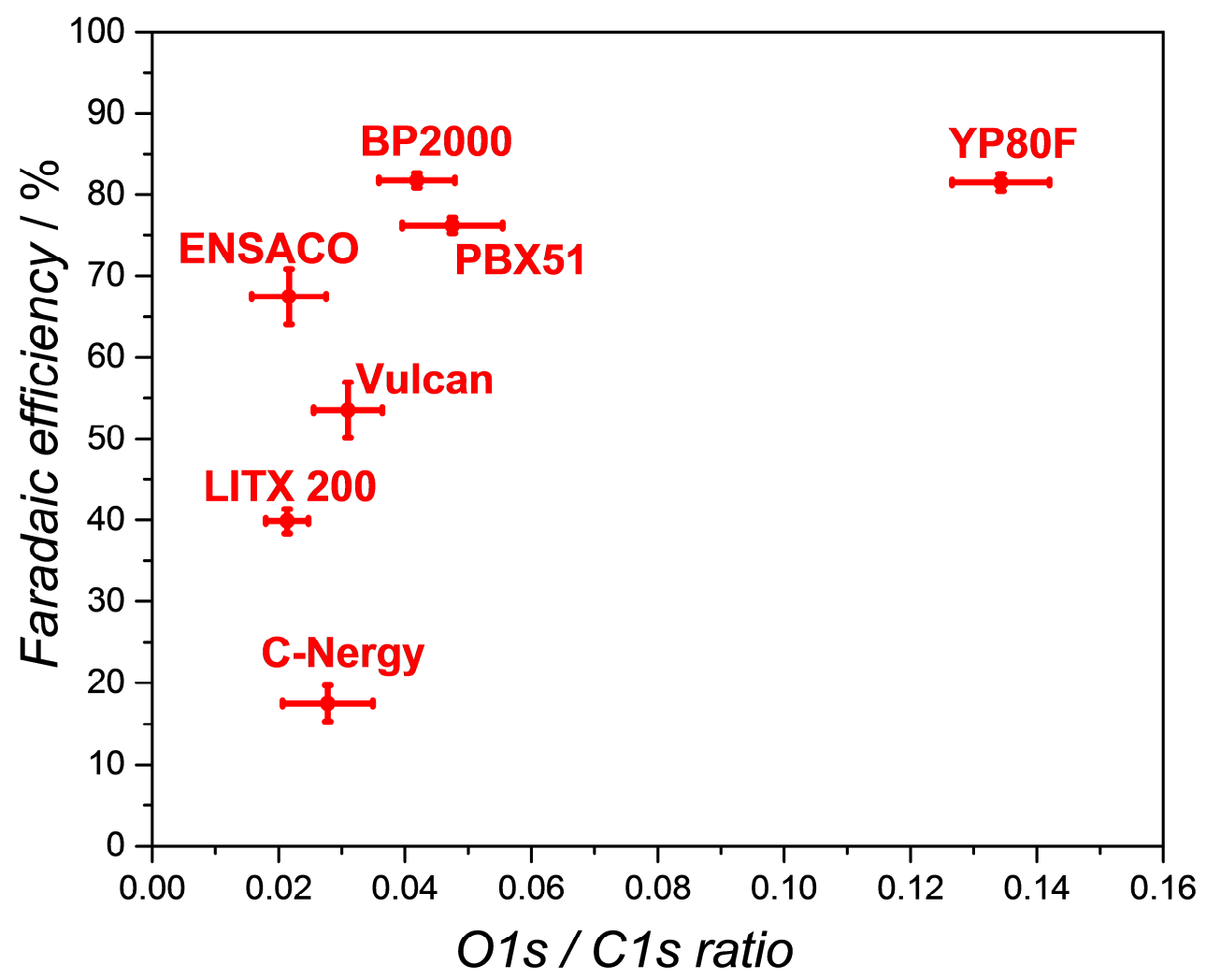




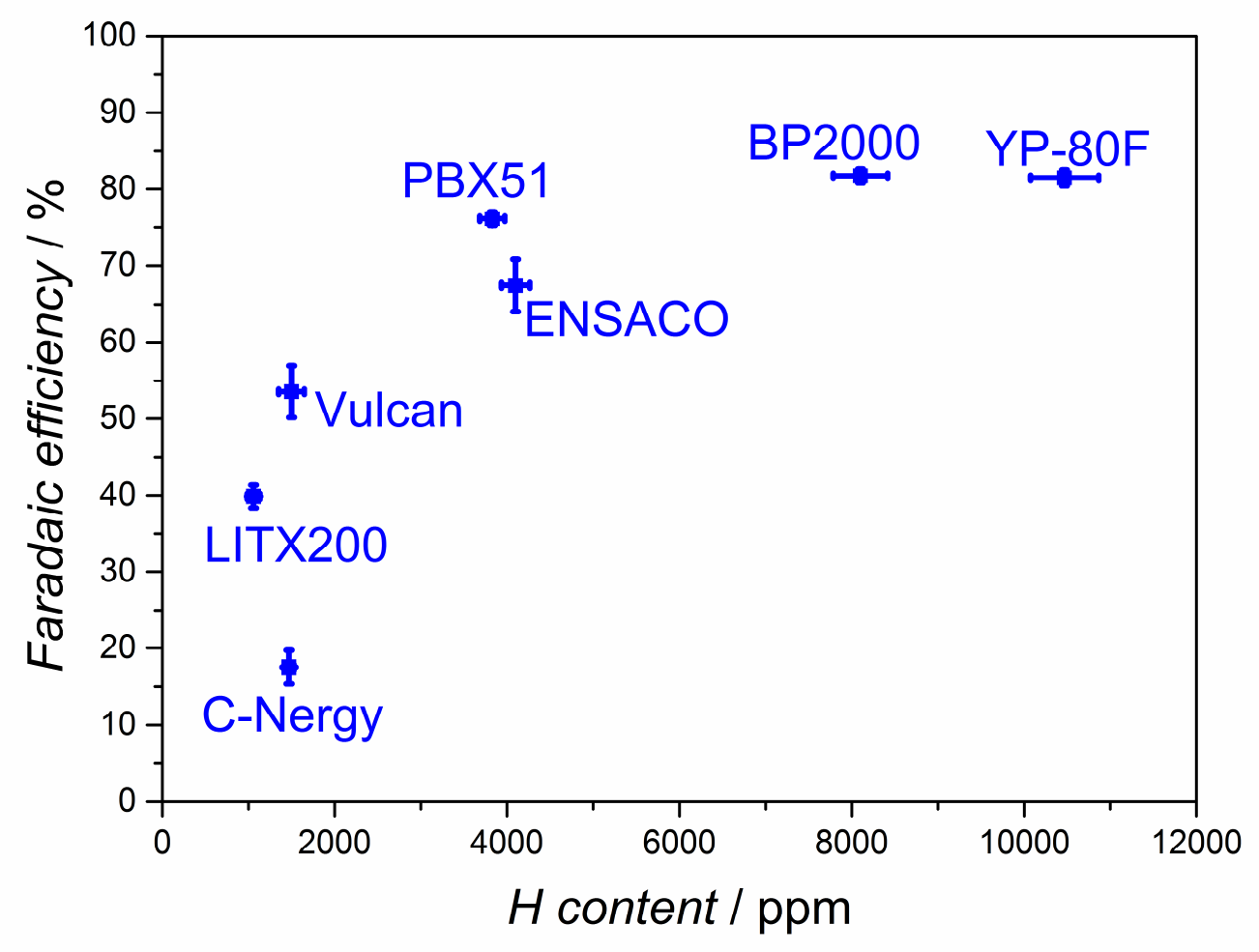




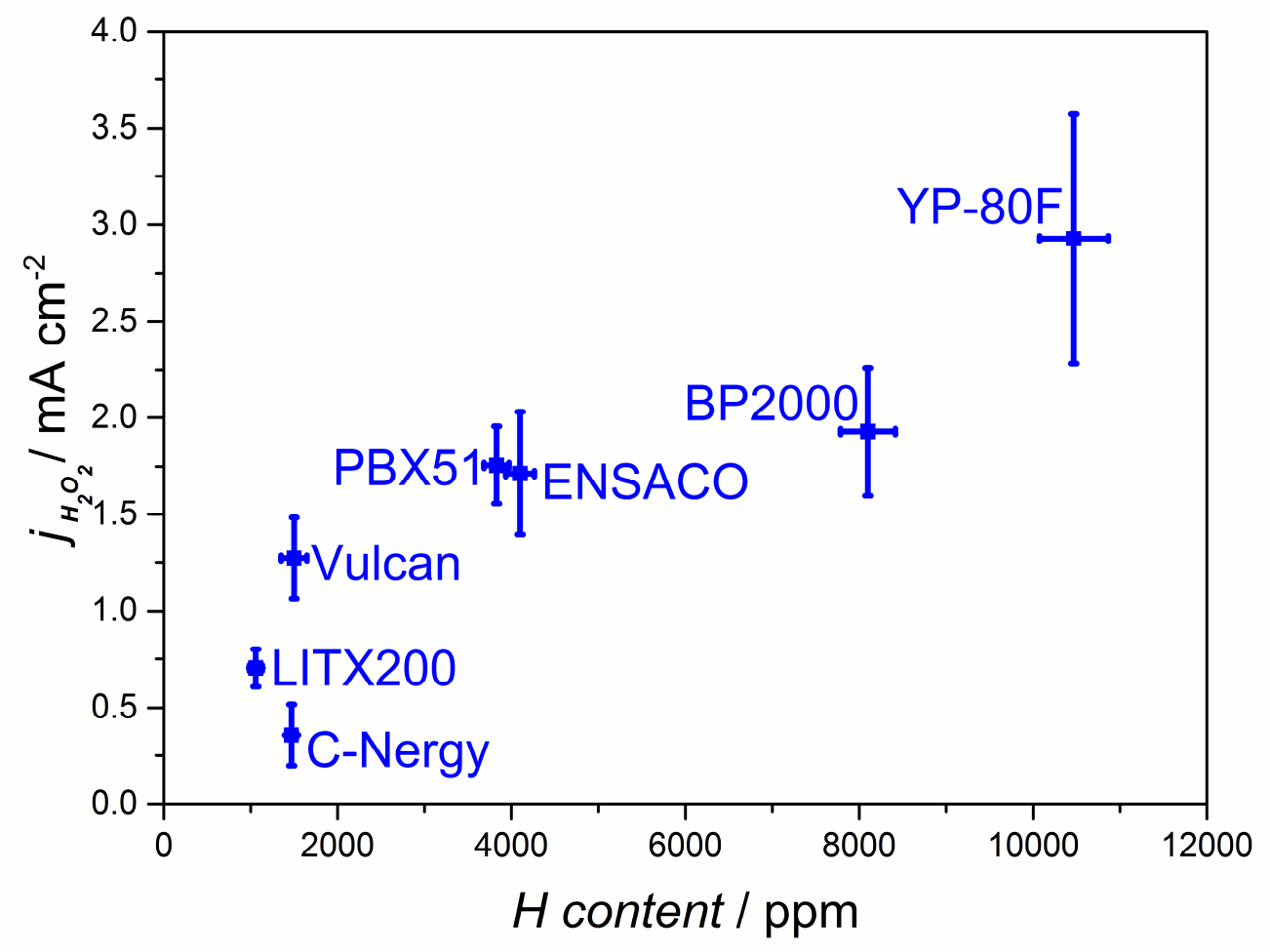




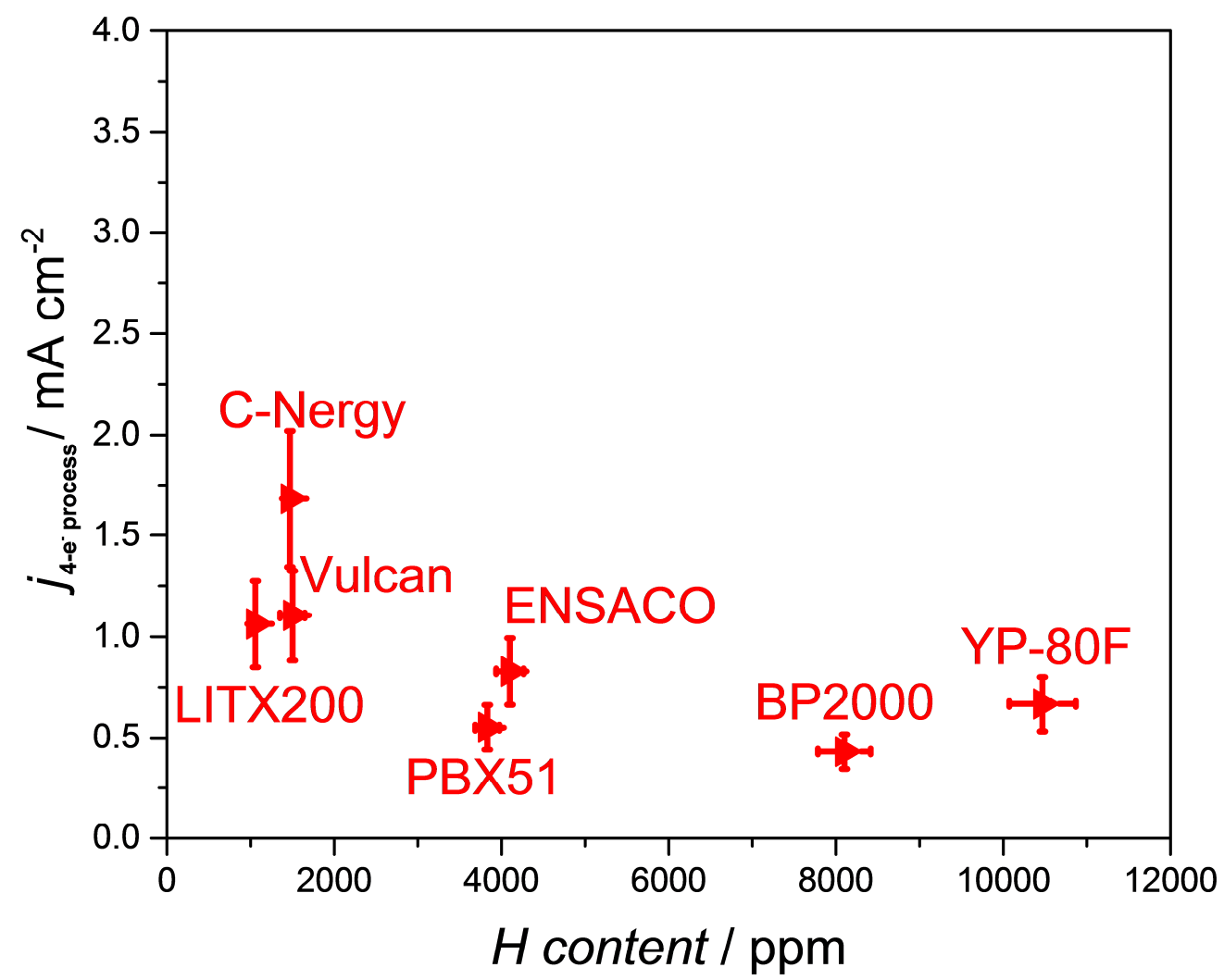




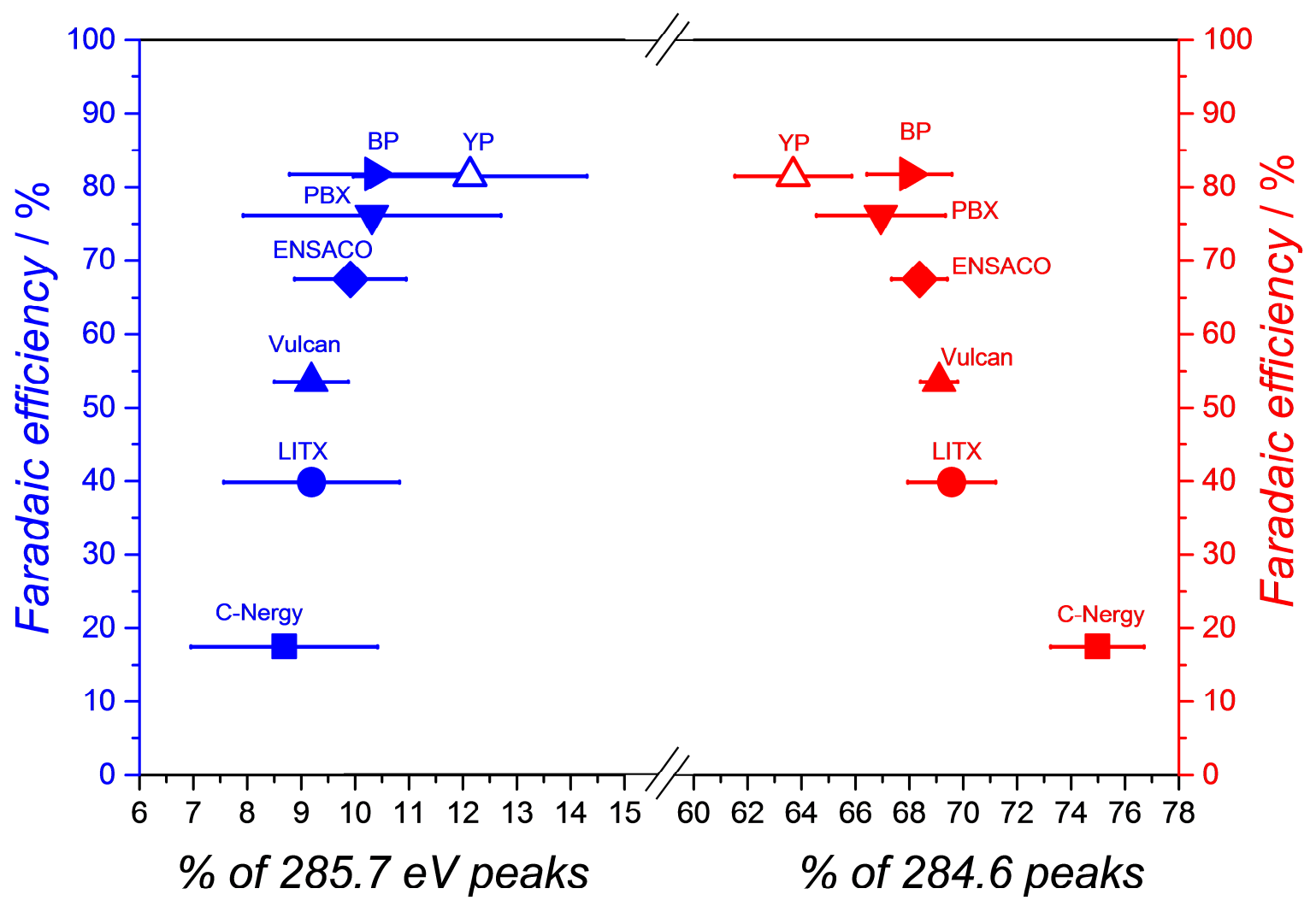




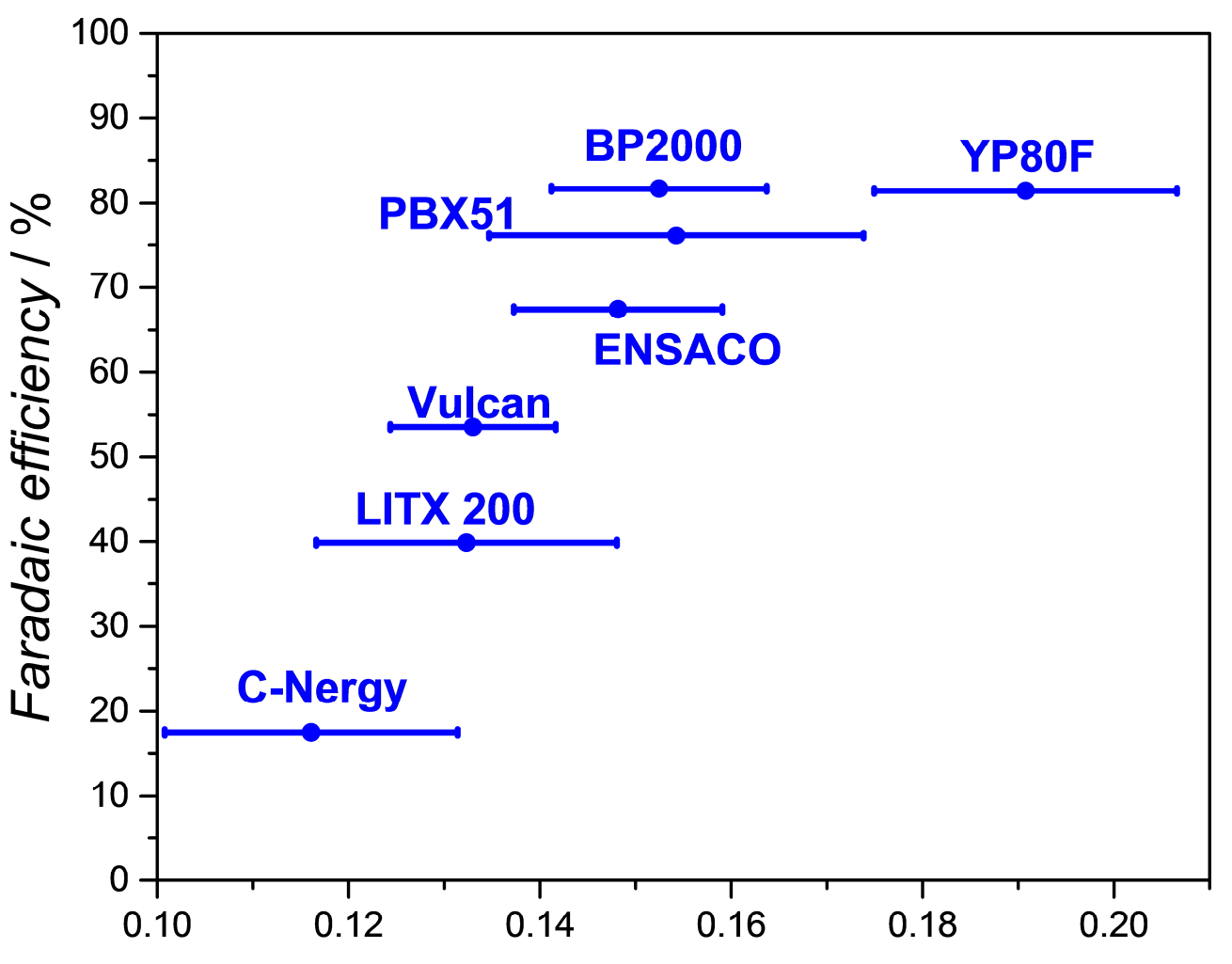

C1s 285.7 eV / 284.6 eV peak ratio 


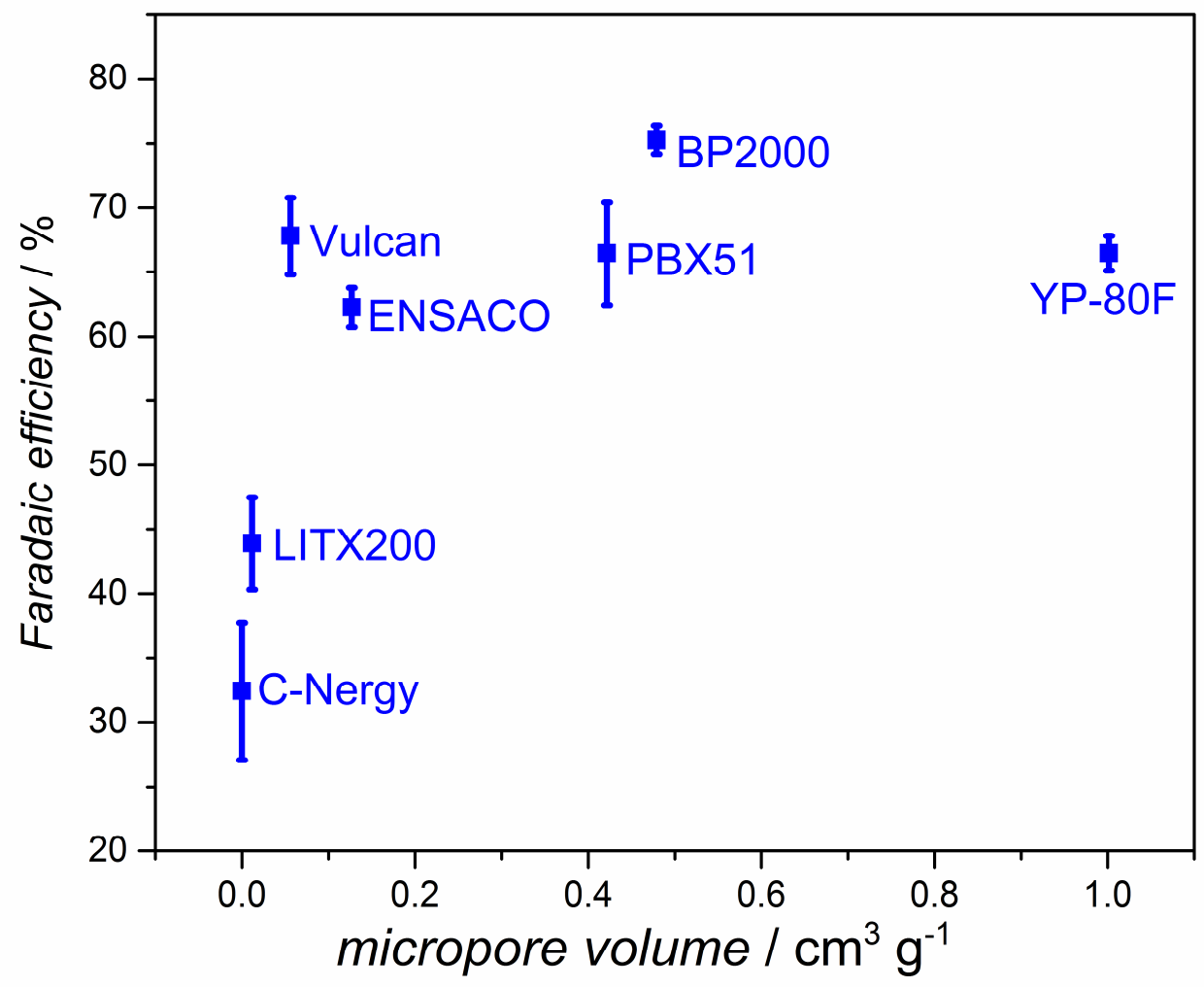




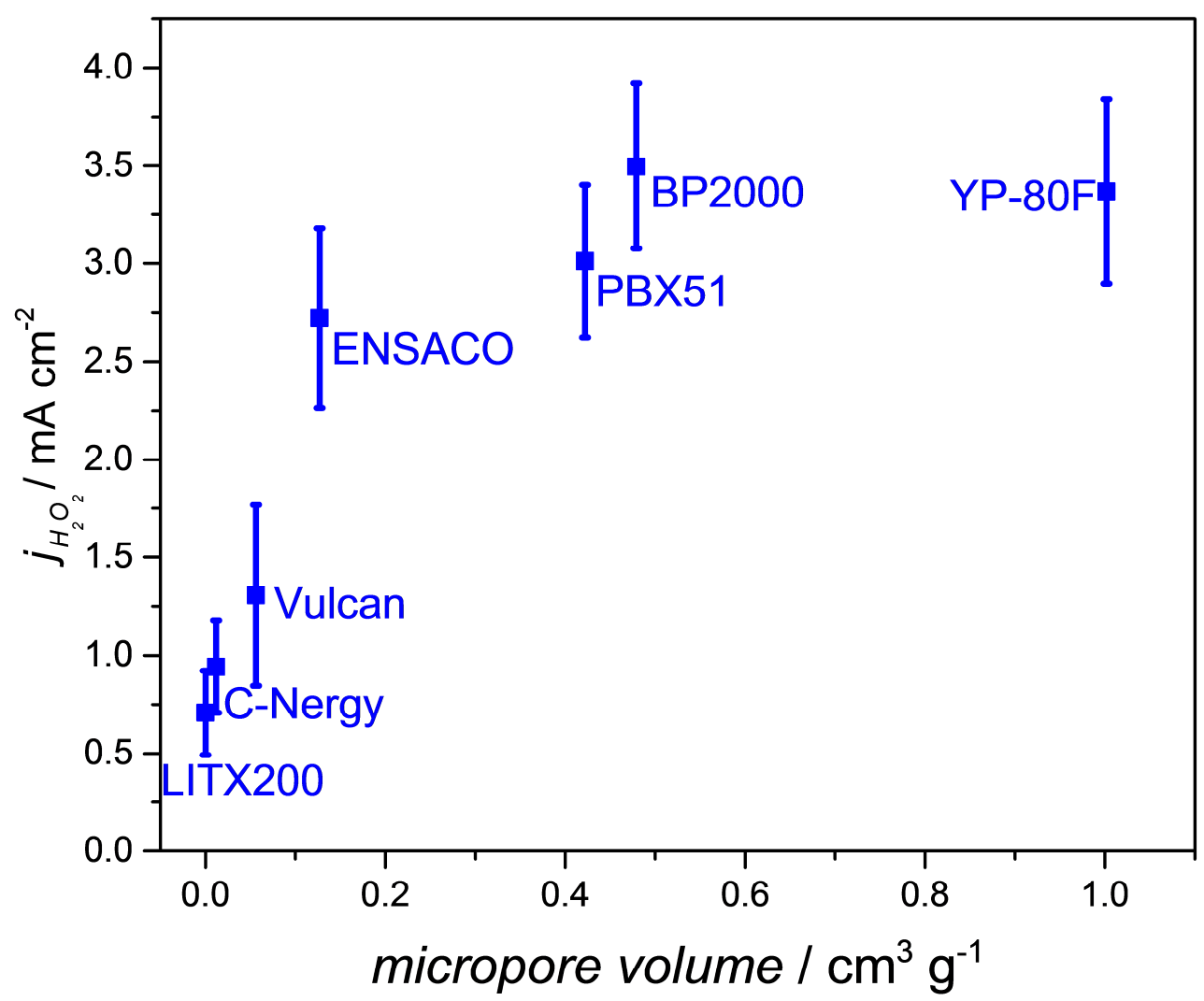




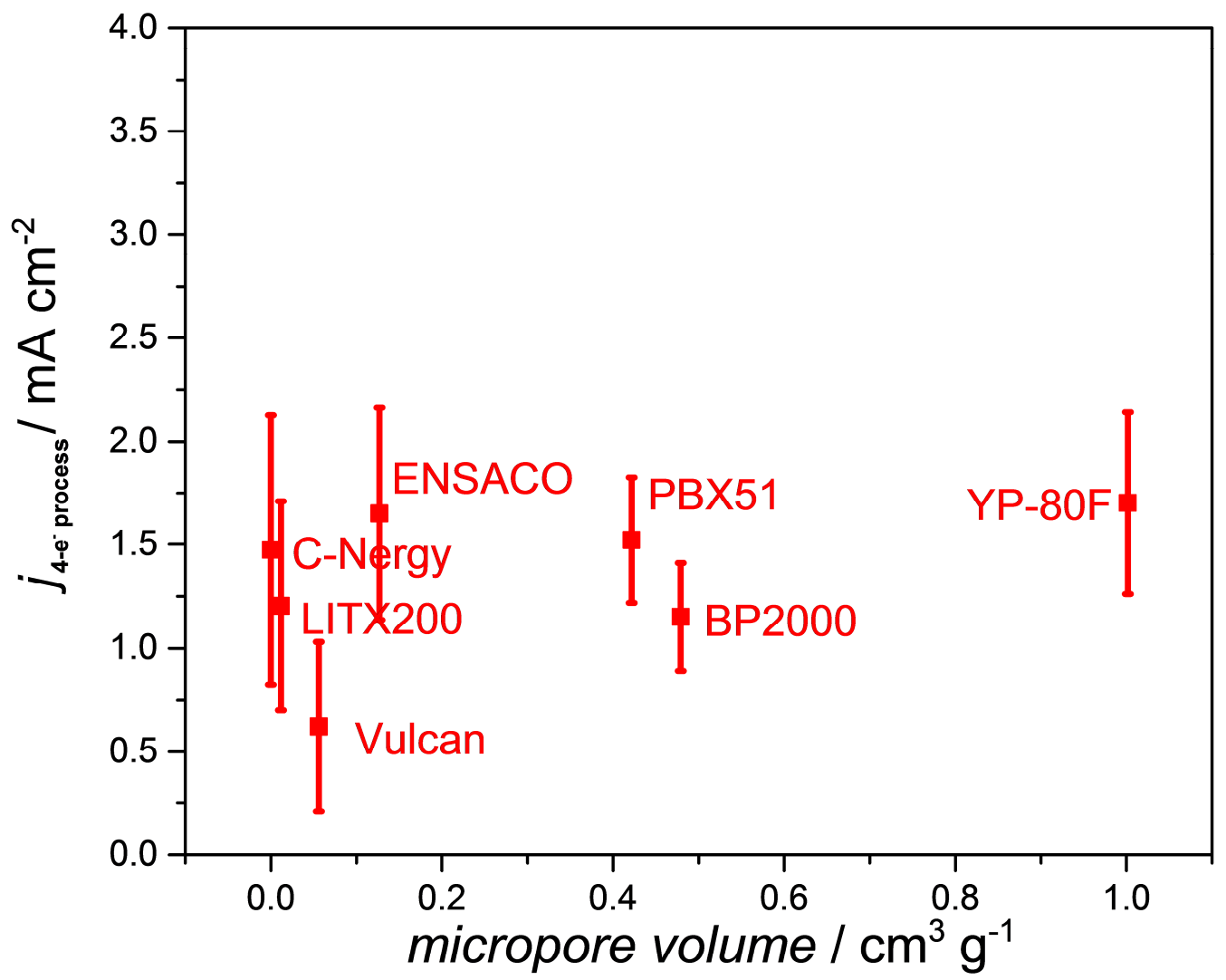

